4 Fatema Calcuttawala ${ }^{*}$, Rahul Shaw ${ }^{2}$, Arpita Sarbajna ${ }^{3}$, Moumita Dutta $^{3}$, Saptarshi Sinha ${ }^{4}$ and

5 Sujoy K. Das Gupta ${ }^{2}$

6

7

\section{A holistic insight of mycobacteriophage induced changes in}

\section{mycobacterial cells}

${ }^{1}$ Department of Microbiology, Sister Nivedita University, Kolkata, India

${ }^{2}$ Department of Microbiology, Bose Institute, Kolkata, India

${ }^{3}$ Division of Electron Microscopy, National Institute of Cholera and Enteric Diseases, Kolkata,

India

${ }^{4}$ Department of Physics, Bose Institute, Kolkata, India

*Corresponding author:

Email: fatema.c@snuniv.ac.in (FC)
Running title: Phage induced changes in mycobacteria

Keywords: Mycobacteriophage, programmed cell death, membrane depolarization, DNA fragmentation, blebbing 


\section{Abstract}

19 Mycobacteriophages are phages that interact with mycobacteria resulting in their killing.

20 Although lysis is the major mechanism by which mycobacteriophages cause cell death, other

21 mechanisms may also be involved. The present study was initiated with the objective of

22 investigating the changes that take place at the cellular level following the infection of

23 mycobacterial cells by phage D29. To investigate this_issue, we took recourse to performing

24 immunofluorescence_and electron microscopic studies. Transmission electron microscopic

25 examination revealed the adsorption of phages on to the surface of mycobacteria, following

26 which penetration of the tail through the thick mycoløic acid layer was seen. At later time points

27 discrete populations of cells at different stages of lysis were observed, which comprised of

28 completely lysed cells, in which the cells were fragmented and those at the early onset stage

29 exhibited formation of membrane pores through which the phages and intracellular contents were

30 released. SEM results also indicated that phages may come out through the entire surface of the

31 cell, or alternatively through gaps in the surface. In some of the images we observed structures

32 that apparently resembled membrane blebs which are normally encountered when cells undergo

33 programmed cell death (PCD). In addition, we observed significant increase in DNA

34 fragmentation as well as membrane depolarization, which are also indicative of occurrence of

35 PCD. As several bacterial PCD pathways are mediated by the toxin-antitoxin (TA) modules, the expression profile of all the TA systems was examined before and after phage infection. Apart

37 from specifically addressing the issue of PCD in mycobacteriophage infected cells, this investigation has led to the development of facile tools necessary for investigating mycobacteriophage-mycobacteria interactions by means of microscopic methods. 


\section{Introduction}

41 Bacteriophages, literally meaning 'bacteria devourers', are the most abundant and diverse

42 biological entities in the world (1). There are $\sim 10^{31}$ phage particles in the biosphere (2). There is

43 a dictum that phages are ubiquitously found where bacteria thrive, thereby playing a fundamental

44 role in regulating bacterial ecology. They are obligate intracellular bacterial parasites, with either

45 a lytic or a lysogenic life cycle (3). Even though they were discovered in 1915 by Frederick

46 Twort, the nature of the existence of the so called "contagium vivum fluidum" and whether it was

47 liquid or particulate remained a topic of contention until they were visualized for the first time in

48 the year 1939 with an electron microscope (EM) by Knoll and Ruska $(4,5)$. Several major

49 milestones were achieved by phage imaging. These comprised of phage classification based on

50 their morphological characteristics and studies on their interaction with the bacterial hosts (6).

51 The therapeutic potential of these transmissible bacteriolytic entities was first identified

52 by their codiscoverer, Félix d'Hérelle (7). Since then phage research became the cradle of

53 fundamental and translational biosciences. There is an increasing interest in the studies focusing

54 on the use of bacteriophages as antibacterial agents against pathogenic bacteria. This is a

55 consequence of the ability of the phage to lyse a bacterial host $(8,9)$. Phage D29 is one such

56 bacteriophage, which infects diverse mycobacteria such as M. smegmatis and M. tuberculosis

57 (10). Belonging to the family Siphoviridae, it typically exhibits a long non-contractile tail (11).

58 The resurgence of $\mathrm{TB}$ and emergence of excessive drug resistant (XDR) and totally drug

59 resistant (TDR) strains has spurred renewed interest in the therapeutic use of

60 mycobacteriophages (12). They can even serve as cornerstones for developing novel diagnostic

61 and preventive strategies (13). D29 is the prototypical model for a mycobacteriophage as it 
62 efficiently adsorbs to the host and begins DNA replication within a few minutes after infection.

63 One-step growth experiments have demonstrated that the length of the latent period, which is the

64 time taken from infection to lysis, is 30-35 minutes in M. smegmatis but is 2-3 hours in $M$.

65 tuberculosis $(14,15)$. The rationale for the choice of $M$. smegmatis as the host is that it is non-

66 pathogenic and grows substantially faster than M. tuberculosis (16). The kinetics of phage

67 infection cycle is directly co-related to its host's generation time and is extended in slow growing bacteria. For instance, DNA synthesis is observed 2-4 minutes after infection by M. smegmatis but is delayed to 20 minutes in case of the slow grower, M. tuberculosis (17). There are recent observations that M. smegmatis $\mathrm{mc}^{2} 155$ is both restriction- and CRISPR-free suggesting that these are positive attributes for discovery of phages. 'host inactivation'. However how this happens still remains obscure. Recent investigations have revealed that multiple mechanisms could be involved some of which are generation of 75 superoxide radicals and induction of thymine less death $(18,19)$. The present study was undertaken in order to gain an insight into the changes in the host cell upon phage infection.

77 Electron microscopy, even though an age old technique, was resorted to, because it is still considered to be the gold standard for viral ultrastructure studies (20). Rather than recruiting phages directly for treatment, they can be used as platforms for drug 81 discovery. Phages have evolved multiple strategies for interfering with bacterial growth.

82 Understanding the targets that phages use in inhibiting bacterial growth has a clear therapeutic 83 implication. In this study we focus on the interaction between mycobacteriophage and 


\section{Materials and Methods}

\section{Bacteria, bacteriophage and media}

Infection experiment was performed using Mycobacterium smegmatis $\mathrm{mc}^{2} 155$ as the host strain and mycobacteriophage D29, which was obtained as a kind gift from Ruth McNerney (LSHTM Keppel Street, London, United Kingdom). Middlebrook 7H9 medium (Difco) supplemented with $0.2 \%$ glycerol, $0.25 \%$ bovine serum albumin (BSA) (HiMedia Laboratories, India) and 0.01\% Tween 80 was used for growing mycobacterial cells. Phage infection was carried out in the same medium except that Tween 80 was omitted and $2 \mathrm{mM} \mathrm{CaCl}_{2}$ was added to the medium. MB7H9 hard agar plates were used for colony counting. The hard agar was overlaid with soft agar containing $2 \mathrm{mM} \mathrm{CaCl}_{2}$, for plaque assay.

\section{Phage infection assay}

Phages were amplified by the confluent lysis method followed by suspension in SM buffer. Phage purification was done by performing $\mathrm{CsCl}$ density gradient centrifugation, followed by dialysis using a dialysis buffer (50mM Tris-Cl (pH 8.0), $10 \mathrm{mM} \mathrm{NaCl}, 10 \mathrm{mM} \mathrm{MgCl}$ ). $M$. smegmatis cells were infected with phage D29 at a multiplicity of infection (MOI) of 1. Aliquots were collected at different time points and centrifuged at $15,700 \mathrm{Xg}$ for $5 \mathrm{~min}$, the pellet and supernatant fractions were separated and the number of PFUs present in the pellet (infectious center) and the supernatant (free phage) were determined separately. The sum of the two values 
at time zero, immediately after phage addition, was considered as the input PFU. The MOI was determined by dividing the input PFU count by the total viable cell count, CFU, which was determined by plating the host cells on the same day.

\section{Cloning and expression of mycobacteriophage D29 gene 17}

The gene encoding the major head subunit gp17, was PCR amplified using the primers D2917F and D2917R (Table 1) from mycobacteriophage D29 genomic DNA and subsequently cloned into the BamHI-HindIII site of the expression vector pET-28a (Novagen). The recombinant protein had a $\mathrm{His}_{6}$ tag at the N-terminal end.

\section{Table 1 List of primers used in the study}

\begin{tabular}{|l|l|}
\hline \multicolumn{1}{|c|}{ Target } & \multicolumn{2}{c|}{ Primer (5'-3') } \\
\hline Primers used for cloning the gene encoding the major head subunit gp17 of phage D29 \\
\hline D2917F & CGGGATCCATGGCCGCAGGCAC \\
\hline D2917R & CCCAAGCTTTCAGCCCTCGCCGC \\
\hline Primers used for RT-PCR and qRT-PCR \\
\hline mazE-F & TGACCGAGTACGCCGACATC \\
\hline mazE-R & GTCCCAGTCGACGGAGATCG \\
\hline mazF-F & GCGCGGCGATATCTACACC \\
\hline mazF-R & CGGCGATTCCCAGAAAAACC \\
\hline phd-F & TCGACGAAGCCGAGATGG \\
\hline phd-R & GTTGAGCTCAGCCGAACG \\
\hline doc-F & GGATCGATCGCTTTTGGCGG \\
\hline doc-R & AATCCAGGTCGCAGTCACGG \\
\hline vapB-F & TCTAAGCATCAAACACCCGGA \\
\hline
\end{tabular}




\begin{tabular}{|l|l|}
\hline vapB-R & CGTCGTAGCCCAGGATCG \\
\hline vapC-F & GTTGCCATCTTGACCGACG \\
\hline vapC-R & GGTGAGCCGAAAAGCCT \\
\hline $16 \mathrm{~S}-\mathrm{F}$ & CTGGGACTGAGATACGGC \\
\hline $16 \mathrm{~S}-\mathrm{R}$ & ACAACGCTCGGACCCTAC \\
\hline
\end{tabular}

114

\section{Purification of recombinant protein}

The plasmid construct made for over-expressing the protein gp17 was transformed into $E$. coli BL21(DE3). The transformants resistant to kanamycin $(50 \mu \mathrm{g} / \mathrm{ml})$ were cultured in the presence of the antibiotic at $37^{\circ} \mathrm{C}$. At an $\mathrm{OD}_{600}$ of 0.5 , isopropyl- $\beta$-D-thiogalactopyranoside (IPTG) was added at a final concentration of $0.5 \mathrm{mM}$. The bacterial cells were induced at $37^{\circ} \mathrm{C}$ for $3 \mathrm{hrs}$. Bacterial pellets were obtained by centrifugation at $10,000 \mathrm{Xg}$ for $15 \mathrm{~min}$. Cells harvested by centrifugation were lysed by sonication. Protein purification was performed using $\mathrm{Ni}^{+2}-\mathrm{NTA}^{2}$ agarose affinity chromatography according to standard protocol (Qiagen).

\section{Raising antibody in rabbit}

Polyclonal antibodies were raised against affinity-purified gp17 protein which was isolated under denaturing conditions in the presence of $8 \mathrm{M}$ urea. The protein sample was gel purified and injected into rabbit. Pre-immune and immune sera were drawn and the specificities of the sera thus obtained were verified by Western blotting.

\section{Immunofluorescence microscopy studies}


At both early and late stages of infection, cells were harvested, washed with PBS and then fixed in $4 \%(\mathrm{w} / \mathrm{v})$ paraformaldehyde in PBS for $20 \mathrm{~min}$ at room temperature. After several PBS washes, blocking was performed using the blocking buffer (3\% BSA in PBS) for 15 min. Cells were subsequently treated with primary antibodies in blocking buffer against gp 17 at $4^{0} \mathrm{C}$ for 1 hr. After several washes with PBS, the cells were incubated with Dylight488-labelled goat antirabbit secondary antibodies (Thermo Fisher Scientific, USA) in blocking buffer at $4^{\circ} \mathrm{C}$ for $1 \mathrm{hr}$. After several washes with PBS, cells were stained with 4', 6'-diamidino-2-phenylindole (DAPI) to visualize the nucleic acid. Stained cells were examined by confocal microscopy (Leica TCS SP8).

\section{Transmission Electron Microscopy (TEM) studies}

The interaction between the mycobacteriophage D29 and its host strain was examined by transmission electron microscopy. Infection was performed at an MOI of 1. Samples collected at different stages of infection were negatively stained with $2 \%$ uranyl acetate and examined under a FEI Tecnai 12 Biotwin transmission electron microscope (FEI,Hillsboro,OR,USA) at an accelerating voltage of $100 \mathrm{kV}$.

\section{Scanning Electron Microscopy (SEM) studies}

For scanning electron microscopy, samples were collected and fixed with glutaraldehyde (1.5\% $\mathrm{w} / \mathrm{v}$ ). After centrifugation at $3,300 \mathrm{Xg}$, the pellet was dissolved in $20 \%$ ethanol solution and spread on the glass slide for drying, mounted on aluminium stubs, coated with gold (Edwards) and photographed with a SEM (FEI Quanta 200). 


\section{Membrane depolarization assay by flow cytometry}

Cultures were grown overnight at $37^{\circ} \mathrm{C}$ to an $\mathrm{OD}_{600}$ between $0.2-0.3$ before phage treatment. Infection was done at an MOI of 1. After treatment the sample was collected, washed once and resuspended in $1 \mathrm{ml} 1 \mathrm{X}$ PBS. Staining of cells was performed using $5 \mu \mathrm{l}$ of $\mathrm{DiBAC}_{4}(3)$ (Invitrogen, $0.025 \mathrm{mg} / \mathrm{ml}$ in DMSO) followed by incubation for 15 minutes at room temperature in dark. The intensity of $\mathrm{DiBAC}_{4}$ fluorescence was measured using the FACSVerse (BD) system with a 488-nm argon laser for excitation and a 530+15-nm emission filter.

\section{DNA fragmentation assay by flow cytometry and confocal}

\section{microscopy}

DNA fragmentation was quantified by the TUNEL assay using the ApoDirect kit (BD Biosciences). The enzyme terminal deoxynucleotidyl transferase (TdT) adds fluorescein isothiocyanate deoxyuridine triphosphate (FITC-dUTP) to each 3'-hydroxyl end of fragmented DNA, making it possible to determine the extent of DNA fragmentation by measuring the intensity of fluorescence. For our studies, cells were grown and treated with phage. After washing with PBS, cells were fixed by resuspending them in $1 \mathrm{ml}$ of $1 \%$ paraformaldehyde and incubating on ice for $60 \mathrm{~min}$, following which they were washed with PBS, resuspended in 70\% ethanol and stored at $-20^{\circ} \mathrm{C}$ overnight. On the next day, the cells were centrifuged, ethanol was discarded and the cell pellet was resuspended in $1 \mathrm{ml}$ wash buffer provided in the kit. After two washes using this buffer, the pellet was resuspended in $50 \mu \mathrm{l}$ of a staining solution that comprised of reaction buffer, FITC-dUTP and TdT dissolved in distilled water. The reaction mixture was incubated at $37^{\circ} \mathrm{C}$ for $60 \mathrm{~min}$, gently mixing the sample after every $15 \mathrm{~min}$. The 
reaction was arrested by adding $1 \mathrm{ml}$ of rinse buffer from the kit. The rinse was performed twice followed by addition of $500 \mu \mathrm{l}$ prodium iodide/RNase solution and incubation in the dark for 30 min at room temperature. The PI/RNase treatment reduces RNA-related background, and also reports the DNA content of the labelled cells. The intensity of fluorescence was measured using the FACSVerse (BD) system. An aliquot of the stained cells was centrifuged, resuspended in $1 \mathrm{X}$ PBS and examined by confocal microscopy. (Leica TCS SP8).

\section{RNA extraction, RT-PCR and qRT-PCR}

RNA was extracted from $20 \mathrm{ml}$ of broth culture. Cells were harvested by centrifugation $(13,000 \mathrm{Xg}, 5 \mathrm{~min})$ and re-suspended in $2 \mathrm{ml} \mathrm{TE}$ buffer $(10 \mathrm{mM}$ Tris-HCl pH $8,1 \mathrm{mM}$ EDTA) containing lysozyme at a concentration of $5 \mathrm{mg} / \mathrm{ml}$, followed by incubation at $37^{\circ} \mathrm{C}$ for $30 \mathrm{~min}$. This was followed by addition of $5 \mathrm{ml}$ TRIzol reagent (Invitrogen), $1 \mathrm{ml}$ chloroform and centrifugation at $13,000 \mathrm{Xg}$ for $15 \mathrm{~min}$. The aqueous phase was collected and precipitated by adding 0.7 volumes of cold isopropanol, followed by $70 \%$ ethanol wash. The pellet was dried and re-suspended in $50 \mu \mathrm{l}$ of DEPC treated water. Contaminating DNA was removed by DNaseI digestion (Qiagen) and RNA clean up (RNeasy Mini Kit, Qiagen) performed according to the manufacturer's instructions. RNA quality was assessed by agarose gel electrophoresis and $\mathrm{A}_{260 / 280}$

First strand cDNA synthesis was done from 400 ng RNA using RevertAid Reverse Transcriptase (Fermentas) by random priming according to the manufacturer's instructions. One microliter of cDNA, $0.25 \mathrm{mM}$ dNTPs, $0.2 \mathrm{pmol} / \mu 1$ of each primer and $0.3 \mathrm{U}$ of Taq polymerase were used for $25 \mu \mathrm{l}$ of RT-PCR reaction mixtures. Thermal cycler conditions were: $94^{\circ} \mathrm{C}$ for 5 $\min , 30$ cycles of $94^{\circ} \mathrm{C}$ for $30 \mathrm{sec}, 55^{\circ} \mathrm{C}$ for $30 \mathrm{sec}$ followed by $72^{\circ} \mathrm{C}$ for $7 \mathrm{~min}$ and a final hold at 
$4^{0} \mathrm{C}$. $16 \mathrm{~S}$ rRNA transcript levels were used as endogenous control. The PCR products were analysed by agarose gel electrophoresis.

Real-time analysis was conducted using Power SYBER ${ }^{\mathrm{R}}$ Green PCR Master Mix (Applied Biosystems) in a 7500 Fast Real-Time PCR system (Applied Biosystems). The cycling conditions were: $50^{\circ} \mathrm{C}$ for $2 \mathrm{~min}, 95^{\circ} \mathrm{C}$ for $30 \mathrm{sec}, 55^{\circ} \mathrm{C}$ for $30 \mathrm{sec}, 72^{\circ} \mathrm{C}$ for $45 \mathrm{sec}$. All the primers used for RT-PCR and qRT-PCR are enlisted in Table 1.

\section{Results}

\section{Immunofluorescence microscopic studies of phage host interaction}

The interaction of mycobacteriophage D29 with its host bacterium M. smegmatis mc $^{2} 155$ was visually inspected by means of immunofluorescence microscopy. Antibodies were raised in rabbit against the phage D29 capsid protein gp17. Cells were subjected to immunofluorescence staining using anti-rabbit Dylight488 labelled secondary antibody. Pre-immune serum was found to contain no gp17 specific antibodies, as confirmed by Western blot and confocal microscopy. Our results revealed distinct phage adsorption 30 min post-infection. After 2 hrs, several free phages were observed, indicative of phage release after lysis (Fig 1).

Fig 1. Immunofluorescence microscopy of control and phage infected cells. Phages were detected by staining with polyclonal rabbit serum against gp17 capsid protein, followed by anti-rabbit Dylight488 conjugated secondary antibody and cells were localized by DAPI, which stains the nucleic acid. 
 \\ Phage induced morphological changes in mycobacteria by electron}

\section{microscopy}

Morphological examination of the phage D29 revealed that it had an icosahedral head with a diameter of $\sim 50 \mathrm{~nm}$ and a $\sim 100 \mathrm{~nm}$ long tail, at the distal end of which tail fibers were occasionally observed (Fig 2A). The mycobacterial cells measured $\sim 3-4 \mu \mathrm{m}$ lengthwise and exhibited a typical thick cell envelope (Fig 2B). During the early stages i.e., 30 mins post infection, the adsorption of the phage particles to the host cell was clearly observed. Even though infection was performed at an MOI of 1 , multiple phages were seen adsorbed to the bacterial cell surface (Figs 3A, B, E, F). Phages were attached both at the extremities as well as a localized portion on the surface of the mycobacterial cell. Following phage adsorption, penetration of the tail through the thick mycolic acid layer was observed (Figs 3C and 3D). Once the tail pierced the cell wall, the phages retained their normal appearance for a very short duration of time. PostDNA injection, "ghost" phage particles, which are empty capsids were occasionally found attached to the surface (Figs $3 \mathrm{E}$ and $3 \mathrm{~F}$ ). Distinct protrusions of the membrane, analogous to membrane blebs were also observed (Figs 4A-C). At a later stage, i.e., 2 hrs post infection, several discrete populations of cells were observed. Some cells exhibited several pores in the membrane (Figs 5A-F). Leakage of intracellular contents and release of phages was observed from these pores. Several mature phages were seen clustered and localized close to the host cell (Figs 5C and 5D). These cells may exhibit the onset of lysis. Another population consisting mainly of fragmented cells and cellular debris was seen, representing later stages of lysis (Fig 6). SEM data correlated well with that of TEM (Fig 7). 
Fig 2. TEM image of (A) phage D29 (B) M.smegmatis mc ${ }^{2} 155$ cells.

Fig 3. TEM images showing phage adsorption. Red arrows denote phages.

Fig 4. TEM images showing membrane blebbing during early stages of phage infection.

Blue arrows denote membrane blebs.

Fig 5. TEM images showing cellular changes during early onset of lysis (red arrows denote phages and yellow arrows indicate pore formation in the membrane).

Fig 6. TEM images showing cellular changes during late stages of lysis.

Fig 7. SEM micrographs depicting (A) M. smegmatis $\mathrm{mc}^{2} 155$ (B) Phage adsorption (C)

Membrane blebbing (D) Pore formation in the membrane (E) cell lysis.

\section{Phage infection induces membrane depolarization}

Membrane depolarization is routinely monitored using the membrane potential sensitive dye bis1,3-dibutylbarbituric acid trimethine oxonol $\left(\right.$ DiBAC $\left._{4}\right)$, which diffuses across depolarized yet intact cell membranes, and binds to lipid rich intracellular components. We used $\mathrm{DiBAC}_{4}$ staining together with flow cytometry in order to detect fluorescence in individual dying cells. Polymyxin B $(50 \mu \mathrm{g} / \mathrm{ml})$ treated cells were included as positive control. To our surprise, even the untreated cells exhibited some basal fluorescence. This was later found to be due to the addition of Tween to the culture at the time of inoculation. However, upon 4 hours of phage treatment, the level of $\mathrm{DiBAC}_{4}$ fluorescence increased substantially ( $\sim 4$ fold increase compared to the control set), indicating a loss of membrane potential (Fig 8). 
Fig 8. $\mathrm{DiBAC}_{4}$ (3) staining as a measure of membrane depolarization. Fluorescence

\section{Phage infection induces TUNEL-detectable DNA fragmentation}

DNA fragmentation was evaluated by the dominant method of TUNEL assay using the APODirect kit. The fluorescence of individual cells was measured by flow cytometry. Mycobacterial cells treated with hydroxyurea $(20 \mathrm{mM})$ for 8 hours were used as positive control. In case of phage treated cells, no appreciable DNA fragmentation was observed at the early stages of infection. However, an increase in the percentage of TUNEL positive cells $(\sim 3$ fold increase compared to the control set) indicating an increase in DNA damage was observed after 4 hours of infection (Fig 9). Flow cytometry data was further supported by direct microscopic assessment using PI and FITC to stain the M. smegmatis $\mathrm{mc}^{2} 155$ cells. Phage treated cells stained positively for PI and FITC as compared to control cells which were stained with PI only (Fig 10).

Fig 9. DNA fragmentation detected by the TUNEL assay. UL (Upper Left), UR (Upper Right), LL (Lower Left) and LR (Lower Right) denote the percentage of cells in each of the quadrants. The threshold was set using untreated and unstained M.smegmatis mc $^{2} 155$ cells. 
This data represents the results of one of the three similar experiments. FITC-fluorescein isothiocyanate, SSC-side scatter.

Fig 10. Microscopic analysis of phage infected and control cells stained with the dyes PI and FITC. Scale bars $7.5 \mu \mathrm{m}$.

\section{Expression profiling of toxin-antitoxin systems of the host upon}

\section{phage infection}

Mycobacterium smegmatis contains three putative toxin-antitoxin (TA) systems MazEF, VapBC and Phd/Doc (21). TA modules comprise of a pair of genes usually co-transcribed as an operon, in which the downstream gene encodes the stable toxin and the upstream one encodes the labile antitoxin (22). In our study, the expression profile of all the TA systems was analyzed at two time points, 2 hrs and 4 hrs respectively, upon phage infection. A unified pattern of expression was observed. The RT-PCR results indicated that in general the expression level of all the TA system genes decreased from 2 hrs to 4 hrs (Fig 11) in the phage infected sets. To further ensure that these changes were due to phage infection, PCR was performed using primers for the phage D29 gene encoding gp88 (data not shown). In case of all the samples, no amplification products were observed in the absence of reverse transcriptase, thereby confirming that the products seen by RT-PCR were due to the TA transcripts and not DNA contamination. Quantitative measurement by real-time PCR was done for the VapBC system and the qRT-PCR results were found to be consistent with those obtained by the qualitative end point PCR. A dramatic decrease 
in gene expression was observed upon phage infection (Fig 12) whereas the expression was found to increase marginally in the uninfected controls.

Fig 11. RT-PCR analysis of the various toxin-antitoxin genes of M.smegmatis mc $^{2} 155$. In each case, the name of the target gene is mentioned on the left side of the panel and the time points at which RNA was extracted from the cells are mentioned on the top. To ensure that the bands represent RNA entities and not their DNA counterparts, RT-PCR analysis was performed with samples that were either subjected (+) or not subjected (-) to reverse transcription prior to PCR. As internal control, amplification was done using 16S rRNA primers. U-Untreated, T-D29 phage treated, PC-Positive control, NC-Negative control.

Fig 12. Analysis of VapBC gene expression 2 hrs and 4 hrs after phage D29 infection by qRT-PCR. The expression level of each gene was determined by the comparative $C_{T}$ method after normalizing with a 16S rRNA control. The data were averaged from three independent experiments \pm S.D.

\section{Discussion}

The present investigation was undertaken in order to determine the morphological and physiological changes that mycobacterial cells undergo upon phage infection. Past speculation reveals that for a long time the research with mycobacteriophages possessed a merely phenomenological character, where it was possible to observe productive infection by the phages 
only by scoring for the efficiency of plaque formation (23). However, with the advent of immunofluorescence microscopy, the 'fluorophages' provided a visual alternative for mechanistically dissecting the crucial steps of phage adsorption and lysis, leading to plaque formation $(24,25)$. In this work we examined phage-host interaction at the single-phage, singlecell level and thereby present a new tool for studying different properties of infection propagation at the microscopic level by employing a 'fluorophage'. Even though our work is at its infancy, yet it provides a stepping stone towards performing time lapse experiments under the microscope. This in turn would provide a more precise understanding of the dynamics of infection and render complete knowledge regarding the propagation of infection in real time.

Electron microscopy took our studies on understanding phage-host interaction to a fundamentally new level (26). Right from the past, the mycobacteria-mycobacteriophage system has been considered to be ideal for EM studies because the two-fold obstacle confronted using $E$. coli and their phages could be overcome by using this model system (27). The obstacles comprised of opacity of the $E$. coli cell to electrons, which hindered the observation of the cell interior and the extreme rapidity of lysis, which made it impossible to distinguish between different phases of the infection process (28). However, the electron transparency of mycobacterial cells upon phage attack and prolonged infection cycle of mycobacteriophages acted as positive attributes for EM studies (29). This has made it possible for us to visualize the complete infection process from the beginning till the end, including phage adsorption, penetration of the non-contractile tail through the thick mycolic acid layer, the morphological changes in the infected cells including pore formation during onset of lysis, followed by bursting of the host cells and release of mature phages and intracellular contents. Non-contractile tails are a defining feature of phages belonging to the Siphoviridae family, of which phage D29 is a 
member (11). Another striking observation was that the dimensions of the pores in the membrane were intriguingly smaller than the phages emerging from them. Also, the membrane of the infected mycobacterial cells showed structures resembling membrane blebs, which is a characteristic feature of cells undergoing PCD (30).

PCD is a genetically-determined process characterized by a stereotypical set of morphological hallmarks (31,32). Our results demonstrated that phage infection induced characteristic changes in the host cells, such as DNA fragmentation, membrane depolarization and membrane blebbing that are strikingly reminiscent of eukaryotic apoptosis. Depolarization of the mitochondrial inner membrane is one of the key events which characterize the intrinsic pathway of apoptosis in case of eukaryotes (33). The phage D29 holin-like proteins and the eukaryotic BCL-2 family of proteins seem to utilize similar strategies to disrupt the integrity of the host cell membrane (34). Bacteria are ancestral to mitochondria as evidenced by the endosymbiotic theory $(35,36)$. Thus, taking these similarities into consideration, it is tempting to speculate the possibility of convergent evolution of the machinery that controls PCD in case of prokaryotes and eukaryotes.

Previously, experiments conducted in our laboratory had demonstrated that the decrease in number of viable cells far exceeded the number of cells that undergo lysis upon phage infection. This phenomenon of death without lysis (DWL) was proposed to involve superoxide radical generation but other secondary factors remained unexplored (19). Our results shed light on the possibility of involvement of PCD in causing DWL. However, the existence of PCD in bacteria seems counterintuitive, the main concern being the benefit of maintaining genes that function to mediate self-destruction of a unicellular organism. PCD may have an altruistic role 
under conditions of stress. The primary response of a cell, under stressful conditions, is induction of DNA repair mechanisms. However, if the damage is insurmountable, with the cost of repair exceeding the cost of building a new cell, 'a point of no return' is reached and PCD is the last resort option adopted by the cell. The demise of some cells could promote the survival of its siblings (37). We hypothesize that upon phage infection majority of the cells undergo lysis, but a sub-population undergoes PCD. The small population of surviving cells, depends on the nutrients released by the dead cells, and may eventually become a nucleus for a renewed population. To the best of our knowledge, this is the first study shedding light on the occurrence of PCD in mycobacteria upon phage infection.

In order to unravel the genetic mechanism underlying phage induced mycobacterial PCD, we investigated the involvement of one of its key regulators, the TA module. We specifically focused on TA loci because of their ubiquitous presence in bacterial genomes and their increasingly observed roles under stressful conditions (38). Several studies conducted on the involvement of the mazEF system in induction of PCD have revealed both pro-survival and prodeath functions (39-41). It seems to play a 'Janus role' in determining the fate of a bacterial cell. In our investigation, the TA system genes were found to be universally down regulated upon phage infection.

Collectively our results provide a detailed mechanistic insight into the phage induced mycobacterial cell death. Our study with 'fluorophages' is the beginning of a model system for studying the dynamics of phage-host interaction. The appearance of different hallmarks of a PCD pathway in phage infected cells opens an interesting avenue for future research. The potential of 
382 this pathway can be tapped by targeting it for future development of a new class of

383 antimicrobials for the treatment of TB.

\section{Author Contributions}

FC was instrumental in carrying out the designed experiments and contributed the text and figures in the manuscript. RS provided assistance in performing immunofluorescence microscopy. MD conducted transmission electron microscopy. SD analyzed the data, conceived the idea and approved the final version of the manuscript.

\section{Funding}

FC acknowledges DBT, Govt. of India for her fellowship.

\section{Acknowledgement}

We thank Prabir Halder for his technical assistance and Ranjan K. Dutta for FACS technical support.

\section{References}

1. Salmond GPC, Fineran PC. A century of the phage: past, present and future. Nat Rev Microbiol. 2015 Dec;13(12):777-86.

2. Pope WH, Hatfull GF. Adding pieces to the puzzle: New insights into bacteriophage diversity from integrated research-education programs. Bacteriophage. 2015 Dec;5(4):e1084073.

3. Chibani-Chennoufi S, Bruttin A, Dillmann M-L, Brüssow H. Phage-host interaction: an ecological perspective. J Bacteriol. 2004 Jun;186(12):3677-86. 
4. Lustig A, Levine AJ. One hundred years of virology. J Virol. 1992 Aug;66(8):4629-31.

5. Kruger DH, Schneck P, Gelderblom HR. Helmut Ruska and the visualisation of viruses. Lancet Lond Engl. 2000 May 13;355(9216):1713-7.

6. Almeida GM, Leppänen M, Maasilta IJ, Sundberg L-R. Bacteriophage imaging: past, present and future. Res Microbiol. 2018 Nov;169(9):488-94.

7. Lin DM, Koskella B, Lin HC. Phage therapy: An alternative to antibiotics in the age of multi-drug resistance. World J Gastrointest Pharmacol Ther. 2017 Aug 6;8(3):162-73.

8. Projan S. Phage-inspired antibiotics? Nat Biotechnol. 2004 Feb;22(2):167-8.

9. Abedon ST, García P, Mullany P, Aminov R. Editorial: Phage Therapy: Past, Present and Future. Front Microbiol. 2017;8:981.

10. Ford ME, Sarkis GJ, Belanger AE, Hendrix RW, Hatfull GF. Genome structure of mycobacteriophage D29: implications for phage evolution. J Mol Biol. 1998 May 29;279(1):143-64.

11. Hatfull GF, Cresawn SG, Hendrix RW. Comparative genomics of the mycobacteriophages: insights into bacteriophage evolution. Res Microbiol. 2008 Jun;159(5):332-9.

12. McNerney R, Traoré H. Mycobacteriophage and their application to disease control. J Appl Microbiol. 2005;99(2):223-33.

13. McNerney R. TB: the return of the phage. A review of fifty years of mycobacteriophage research. Int J Tuberc Lung Dis Off J Int Union Tuberc Lung Dis. 1999 Mar;3(3):179-84.

14. Gan Y, Liu P, Wu T, Guo S. Different characteristics between mycobacteriophage Chy1 and D29, which were classified as cluster A2 mycobacteriophages. Indian J Med Microbiol. 2016 Jun;34(2):186-92.

15. McNerney R, Kambashi BS, Kinkese J, Tembwe R, Godfrey-Faussett P. Development of a bacteriophage phage replication assay for diagnosis of pulmonary tuberculosis. J Clin Microbiol. 2004 May;42(5):2115-20.

16. Hatfull GF. The secret lives of mycobacteriophages. Adv Virus Res. 2012;82:179-288.

17. David HL, Clément F, Clavel-Sérès S, Rastogi N. Abortive infection of Mycobacterium leprae by the mycobacteriophage D29. Int J Lepr Mycobact Dis Off Organ Int Lepr Assoc. 1984 Dec;52(4):51523.

18. Ghosh S, Samaddar S, Kirtania P, Das Gupta SK. A DinB Ortholog Enables Mycobacterial Growth under dTTP-Limiting Conditions Induced by the Expression of a Mycobacteriophage-Derived Ribonucleotide Reductase Gene. J Bacteriol. 2016 Jan 15;198(2):352-62.

19. Samaddar S, Grewal RK, Sinha S, Ghosh S, Roy S, Das Gupta SK. Dynamics of Mycobacteriophage-Mycobacterial Host Interaction: Evidence for Secondary Mechanisms for Host Lethality. Appl Environ Microbiol. 2016 Jan 1;82(1):124-33. 
20. Goldsmith CS, Miller SE. Modern uses of electron microscopy for detection of viruses. Clin Microbiol Rev. 2009 Oct;22(4):552-63.

21. Robson J, McKenzie JL, Cursons R, Cook GM, Arcus VL. The vapBC operon from Mycobacterium smegmatis is an autoregulated toxin-antitoxin module that controls growth via inhibition of translation. J Mol Biol. 2009 Jul 17;390(3):353-67.

22. Schuster CF, Bertram R. Toxin-antitoxin systems are ubiquitous and versatile modulators of prokaryotic cell fate. FEMS Microbiol Lett. 2013 Mar;340(2):73-85.

23. Bowman B. Quantitative studies on some mycobacterial phage-host systems. J Bacteriol. 1958 Jul;76(1):52-62.

24. Pavoni E, Vaccaro P, D'Alessio V, De Santis R, Minenkova O. Simultaneous display of two large proteins on the head and tail of bacteriophage lambda. BMC Biotechnol. 2013 Sep 30;13:79.

25. Mayer O, Jain P, Weisbrod TR, Biro D, Ho L, Jacobs-Sera D, et al. Fluorescent Reporter DS6A Mycobacteriophages Reveal Unique Variations in Infectibility and Phage Production in Mycobacteria. J Bacteriol. 2016 Dec 1;198(23):3220-32.

26. Takeya K, Mori R, Nakashima N, Koike M, Toda T. Light and electron microscope studies of Mycobacterium-mycobacteriophage interactions. I. Light microscope studies. J Bacteriol. 1959 Sep;78:307-12.

27. Takeya K, Koike M, Mori R, Yuda Y, Toda T. Light and electron microscope studies of Mycobacterium-mycobacteriophage interactions. II. Electron microscope studies. J Bacteriol. 1959 Sep;78:313-9.

28. Takeya K, Koike M, Mori R, Toda T. Light and electron microscope studies of mycobacterium-mycobacteriophage interactions. III. Further studies on the ultrathin sections. J Biophys Biochem Cytol. 1961 Nov;11:441-7.

29. Schäfer R, Huber U, Franklin RM. Chemical and physical properties of mycobacteriophage D29. Eur J Biochem. 1977 Feb 15;73(1):239-46.

30. Dewachter L, Verstraeten N, Monteyne D, Kint CI, Versées W, Pérez-Morga D, et al. A SingleAmino-Acid Substitution in Obg Activates a New Programmed Cell Death Pathway in Escherichia coli. mBio. 2015 Dec 22;6(6):e01935-01915.

31. Lewis K. Programmed death in bacteria. Microbiol Mol Biol Rev MMBR. 2000 Sep;64(3):503-14.

32. Bayles KW. Bacterial programmed cell death: making sense of a paradox. Nat Rev Microbiol. 2014 Jan;12(1):63-9.

33. Kroemer G, Galluzzi L, Brenner C. Mitochondrial membrane permeabilization in cell death. Physiol Rev. 2007 Jan;87(1):99-163.

34. Rice KC, Bayles KW. Molecular control of bacterial death and lysis. Microbiol Mol Biol Rev MMBR. 2008 Mar;72(1):85-109, table of contents. 
35. Dyall SD, Brown MT, Johnson PJ. Ancient invasions: from endosymbionts to organelles. Science. 2004 Apr 9;304(5668):253-7.

36. Embley TM, Martin W. Eukaryotic evolution, changes and challenges. Nature. 2006 Mar 30;440(7084):623-30.

37. Allocati N, Masulli M, Di Ilio C, De Laurenzi V. Die for the community: an overview of programmed cell death in bacteria. Cell Death Dis. 2015 Jan 22;6:e1609.

38. Yamaguchi Y, Park J-H, Inouye M. Toxin-antitoxin systems in bacteria and archaea. Annu Rev Genet. 2011;45:61-79.

39. Amitai S, Yassin Y, Engelberg-Kulka H. MazF-mediated cell death in Escherichia coli: a point of no return. J Bacteriol. 2004 Dec;186(24):8295-300.

40. Amitai S, Kolodkin-Gal I, Hananya-Meltabashi M, Sacher A, Engelberg-Kulka H. Escherichia coli MazF leads to the simultaneous selective synthesis of both "death proteins" and "survival proteins." PLoS Genet. 2009 Mar;5(3):e1000390.

41. Erental A, Sharon I, Engelberg-Kulka H. Two programmed cell death systems in Escherichia coli: an apoptotic-like death is inhibited by the mazEF-mediated death pathway. PLoS Biol. 2012;10(3):e1001281.

7

(

9

91


Control
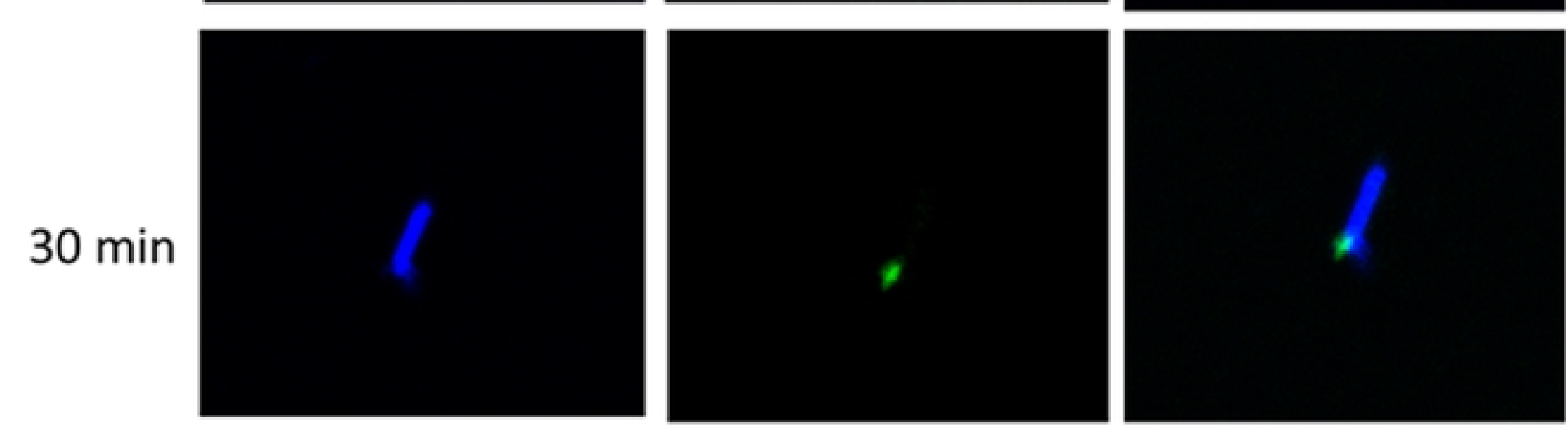

$120 \mathrm{~min}$
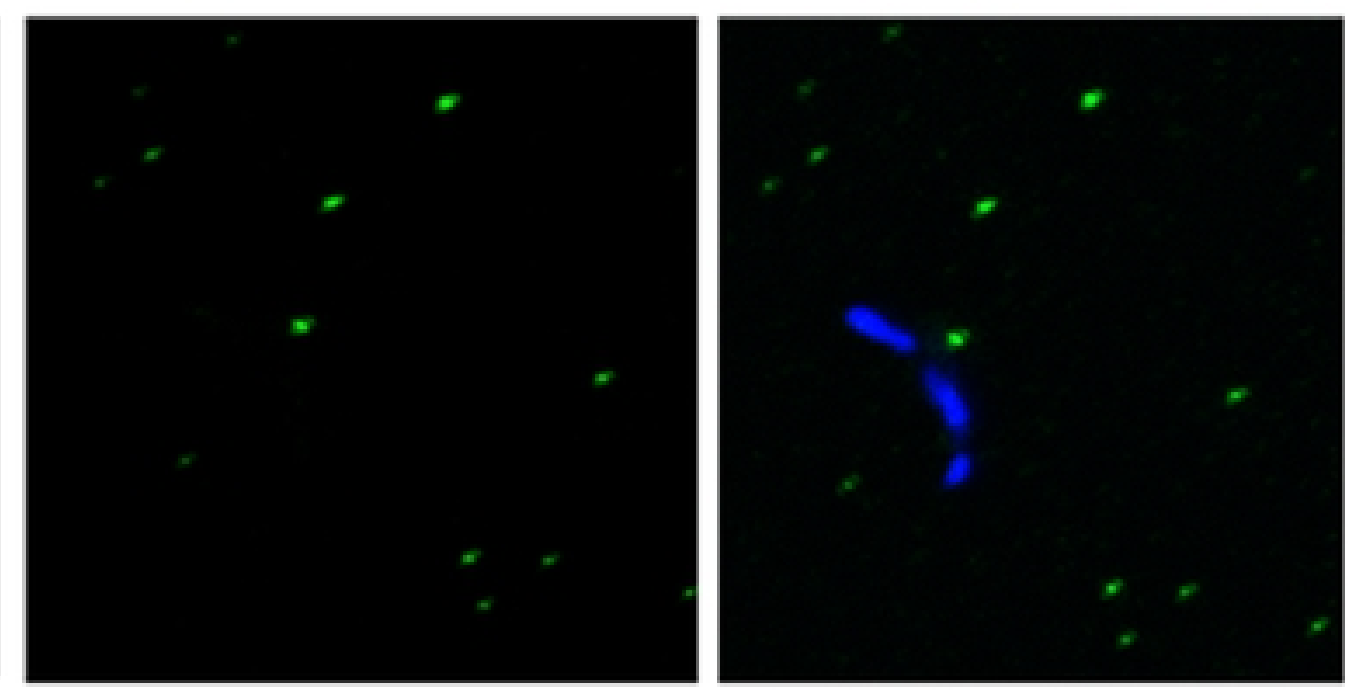

Figure 1 


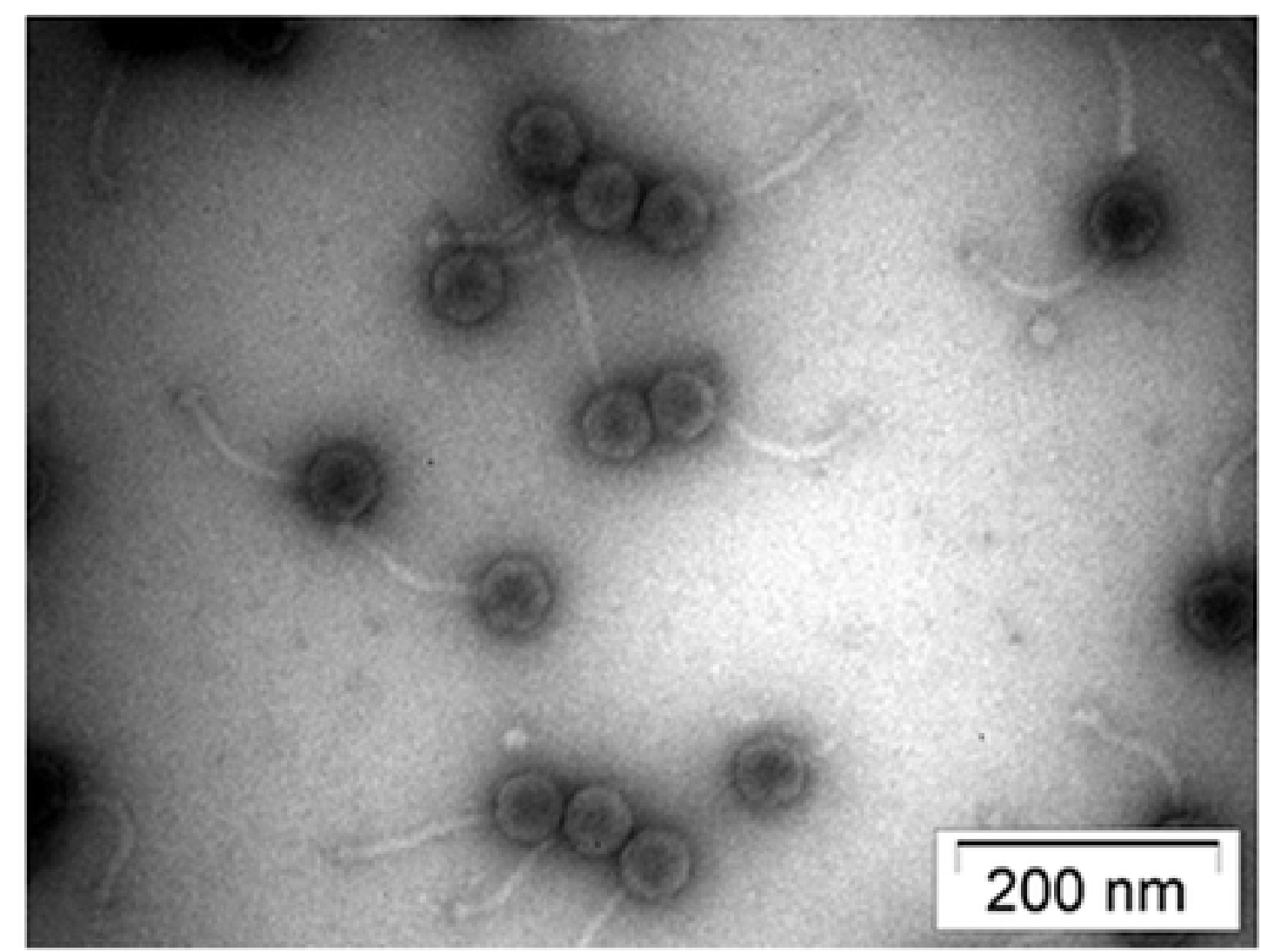

(A)

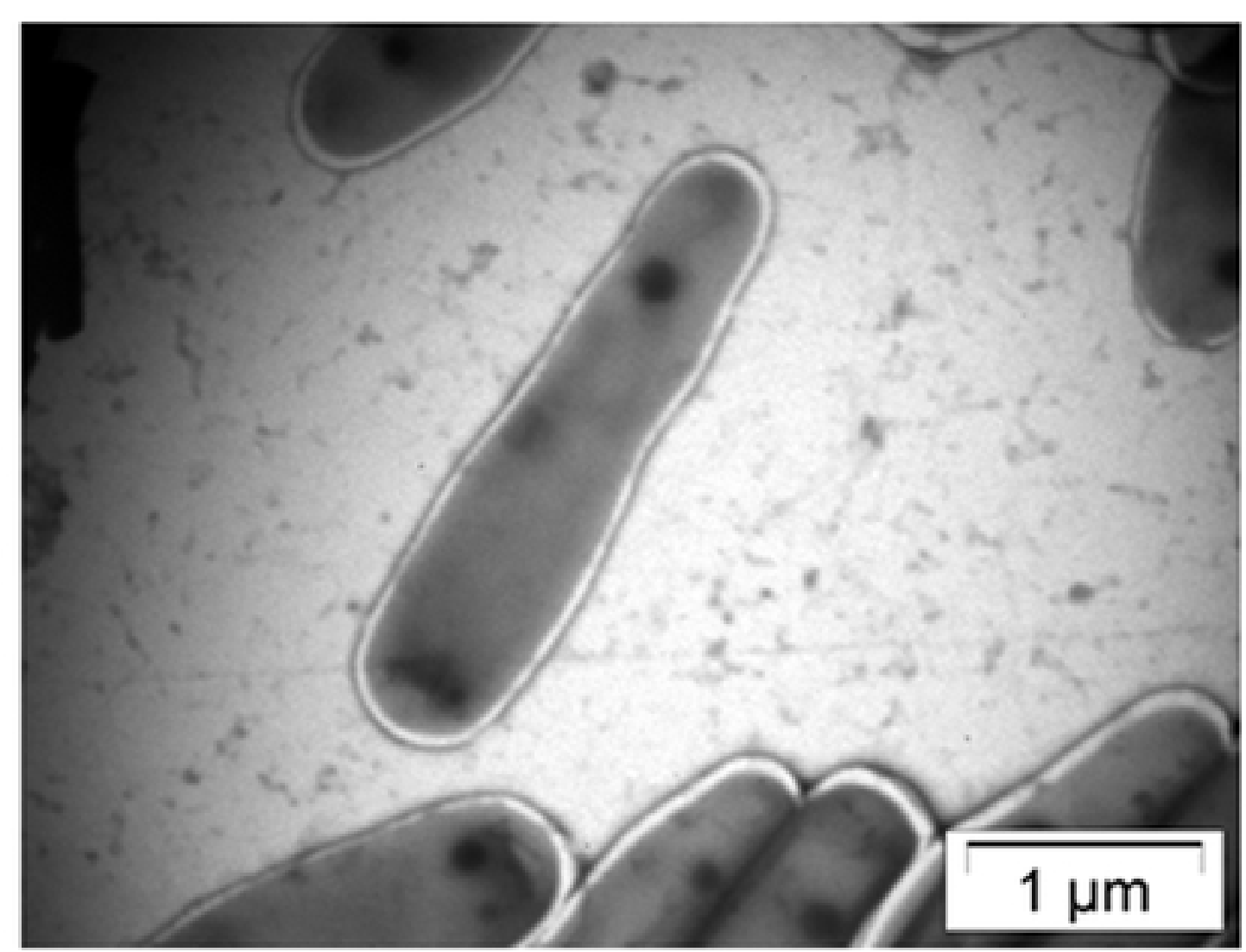

(B)

Figure 2 


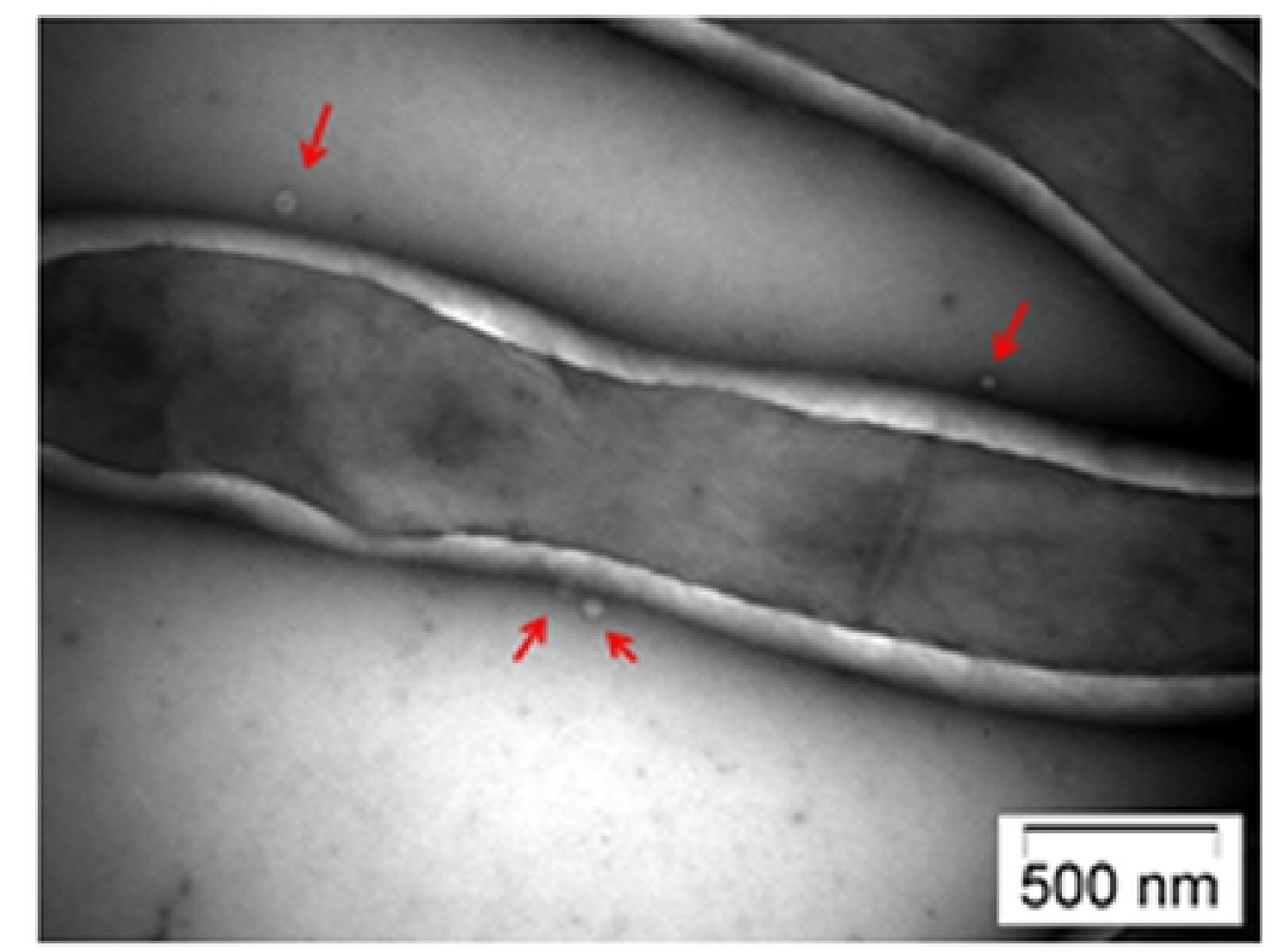

(A)

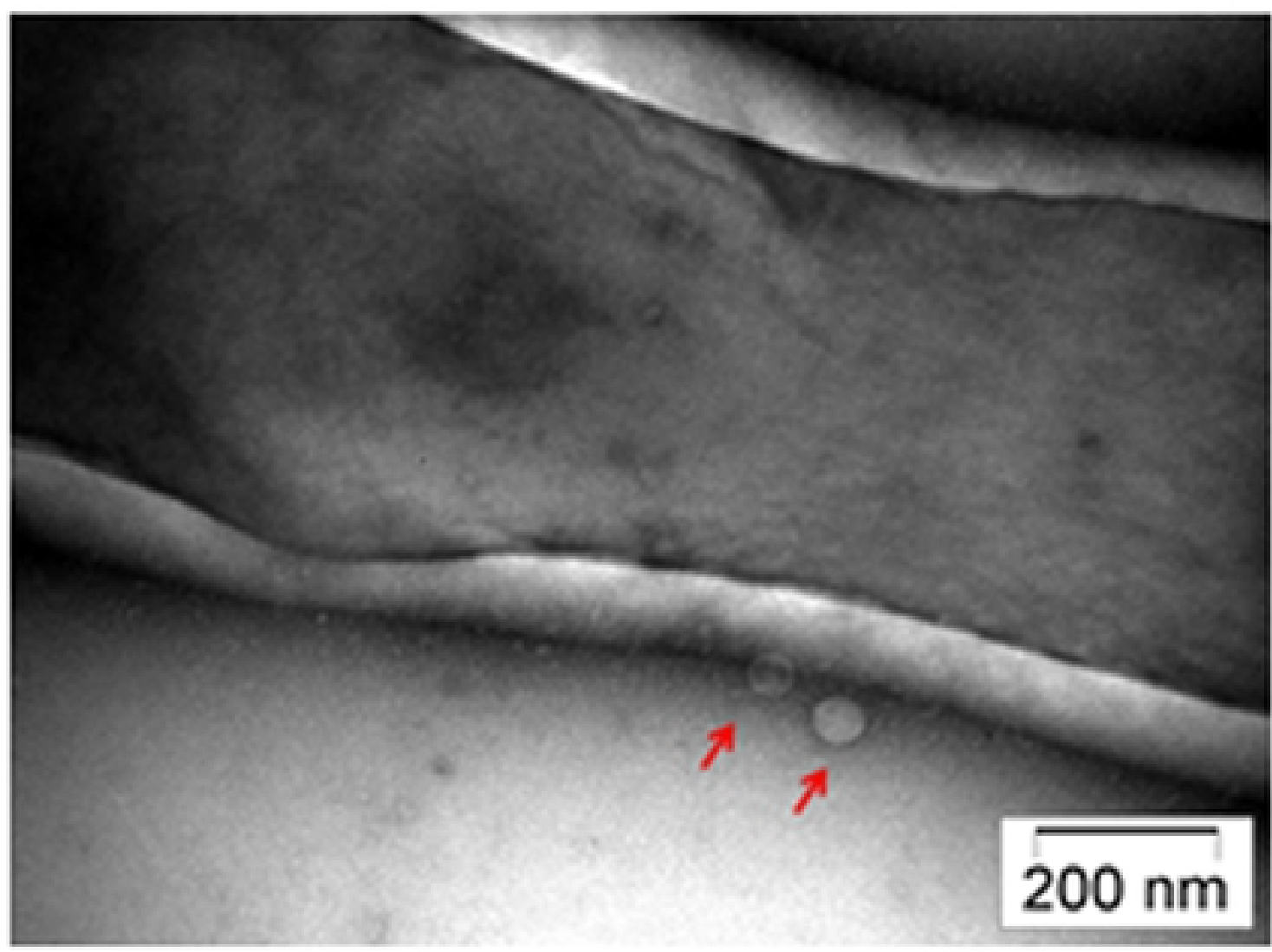

(B)

bioRxiv preprint doi: https://doi.org/10-1401/2021.10.21.465286; this version posted October 21, 2021\% The copyright holder for this preprint

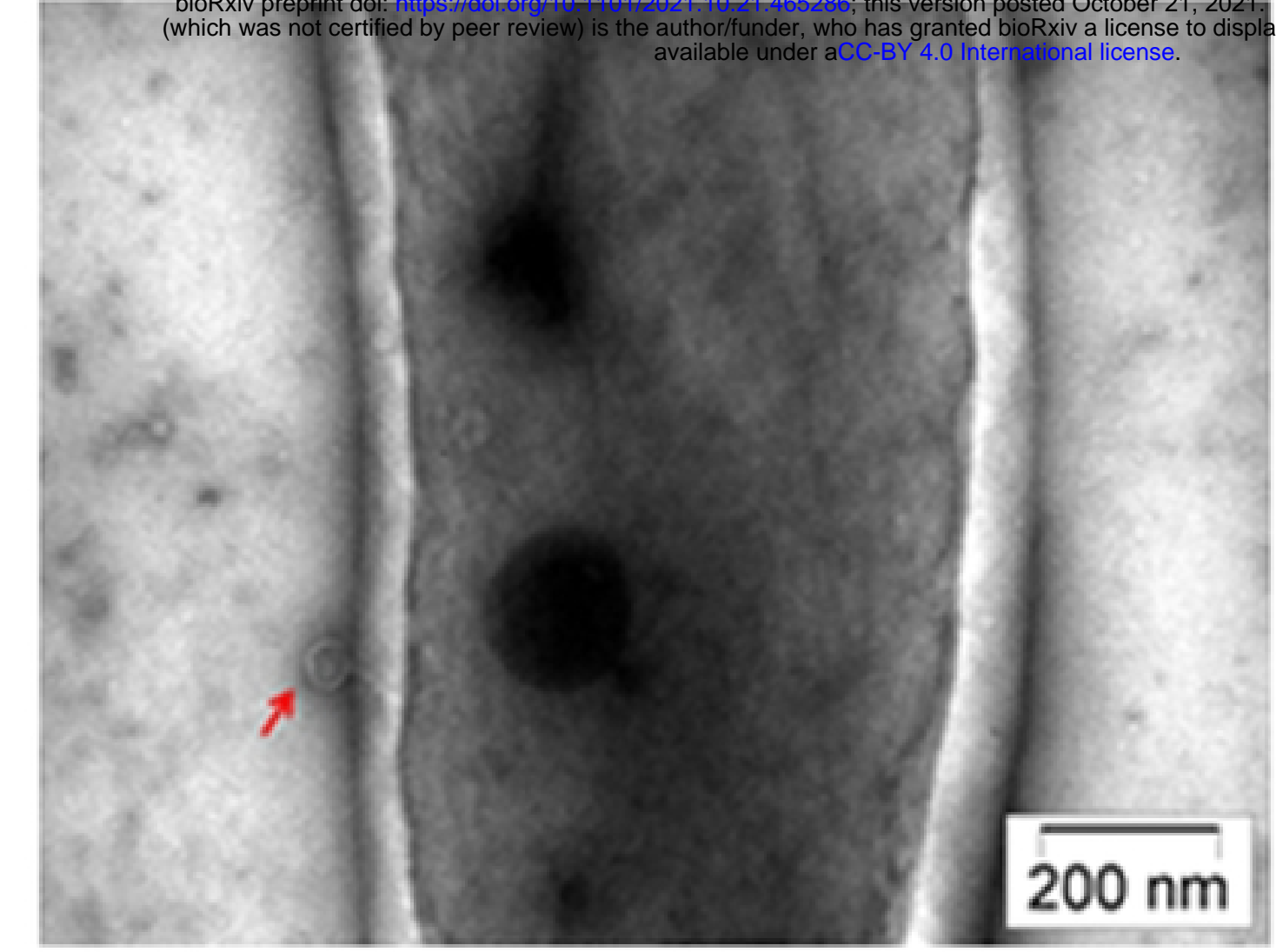

(C)

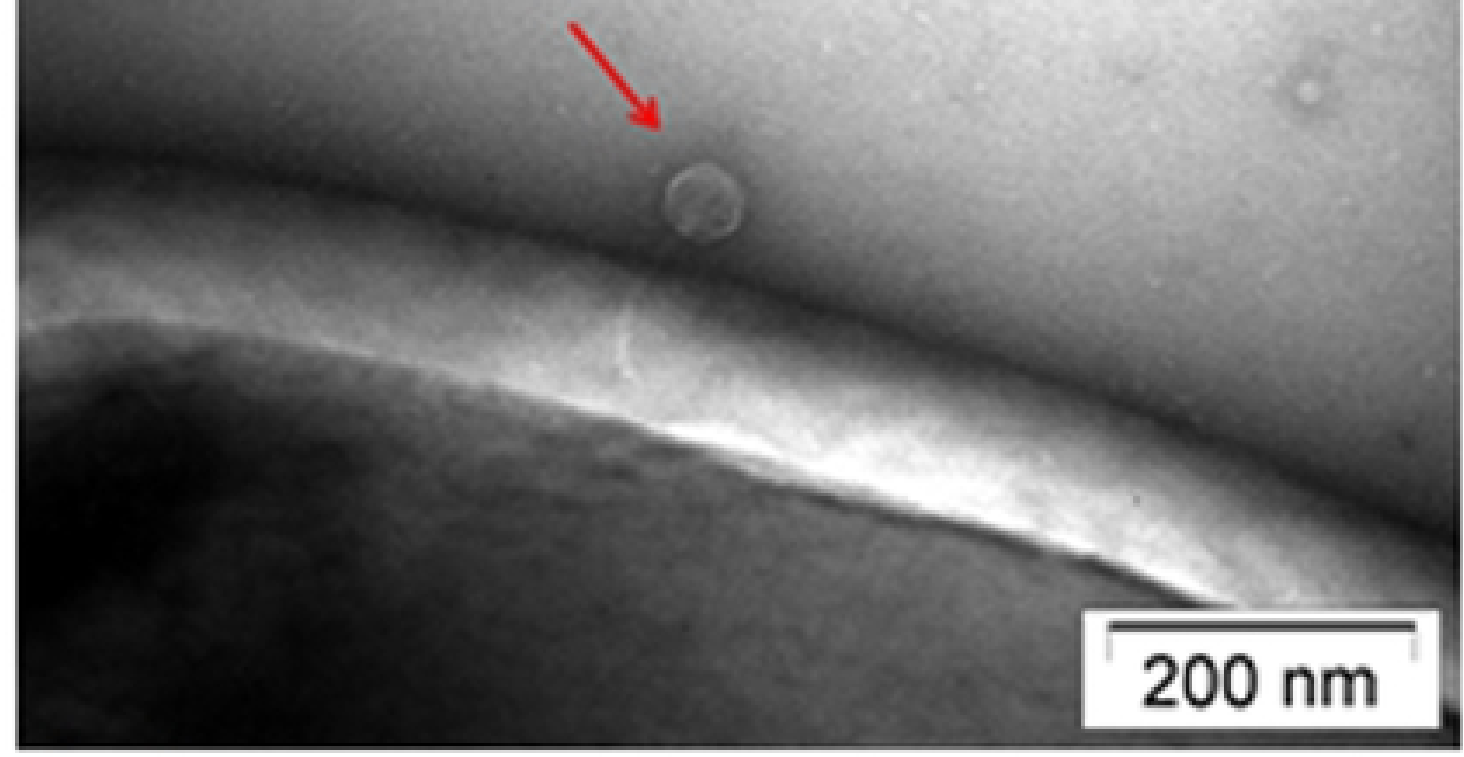

(D)
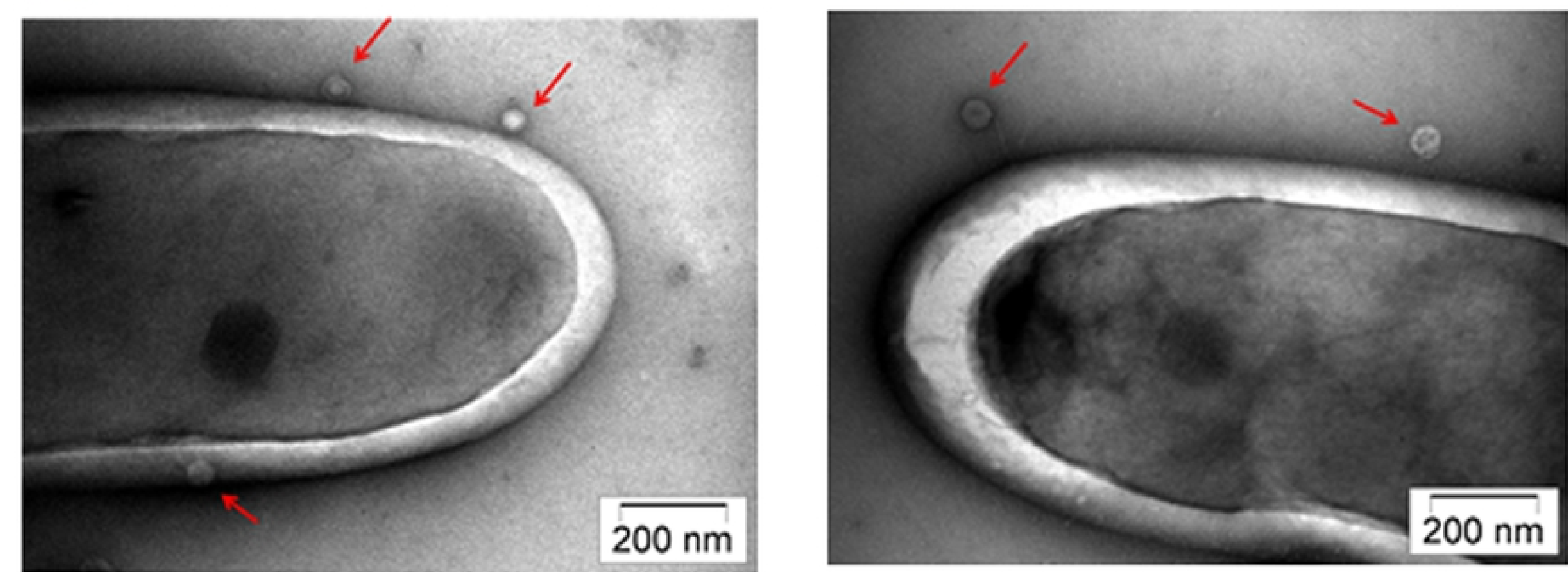

(E)

(F)

Figure 3 


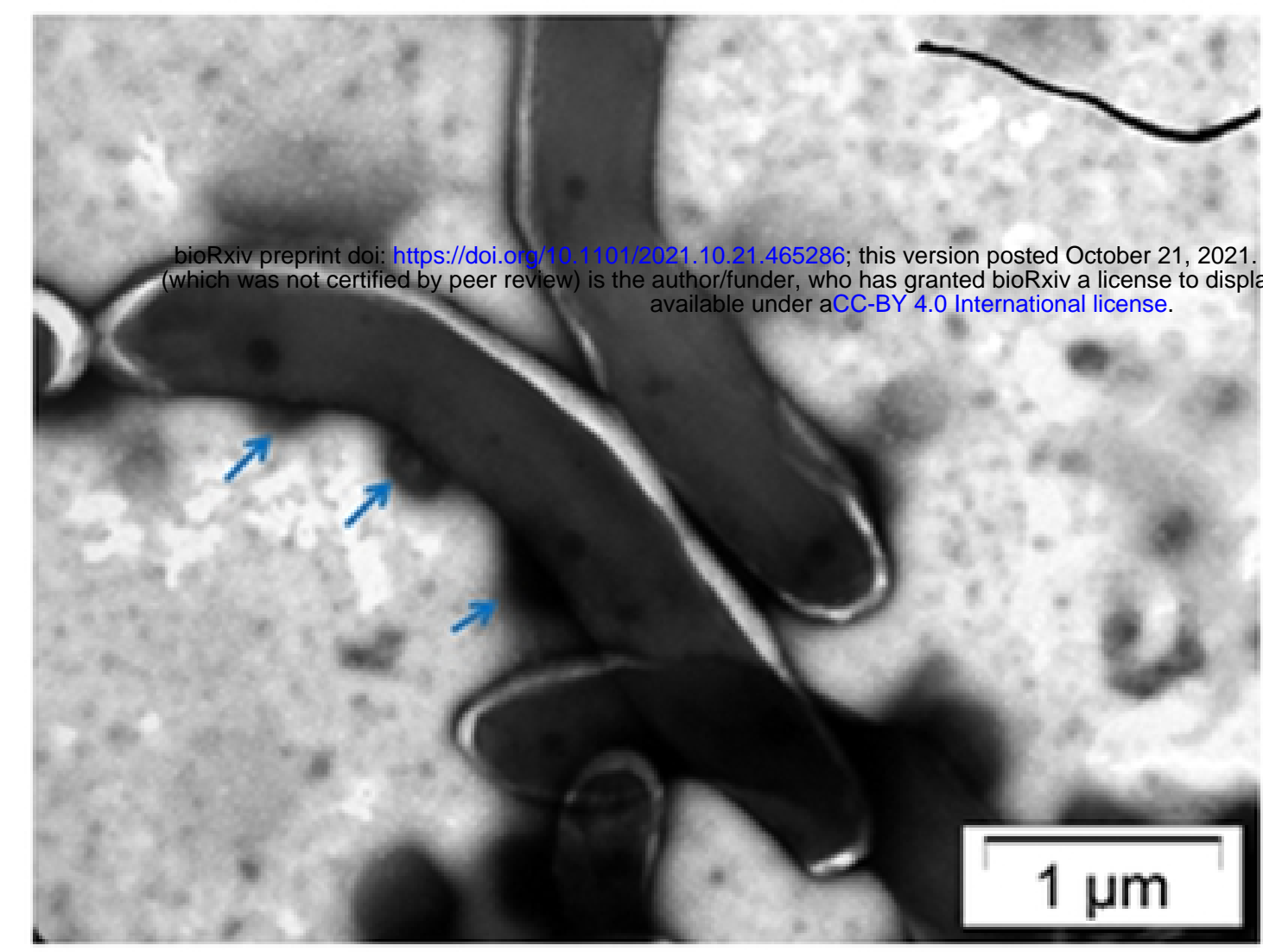

(A)

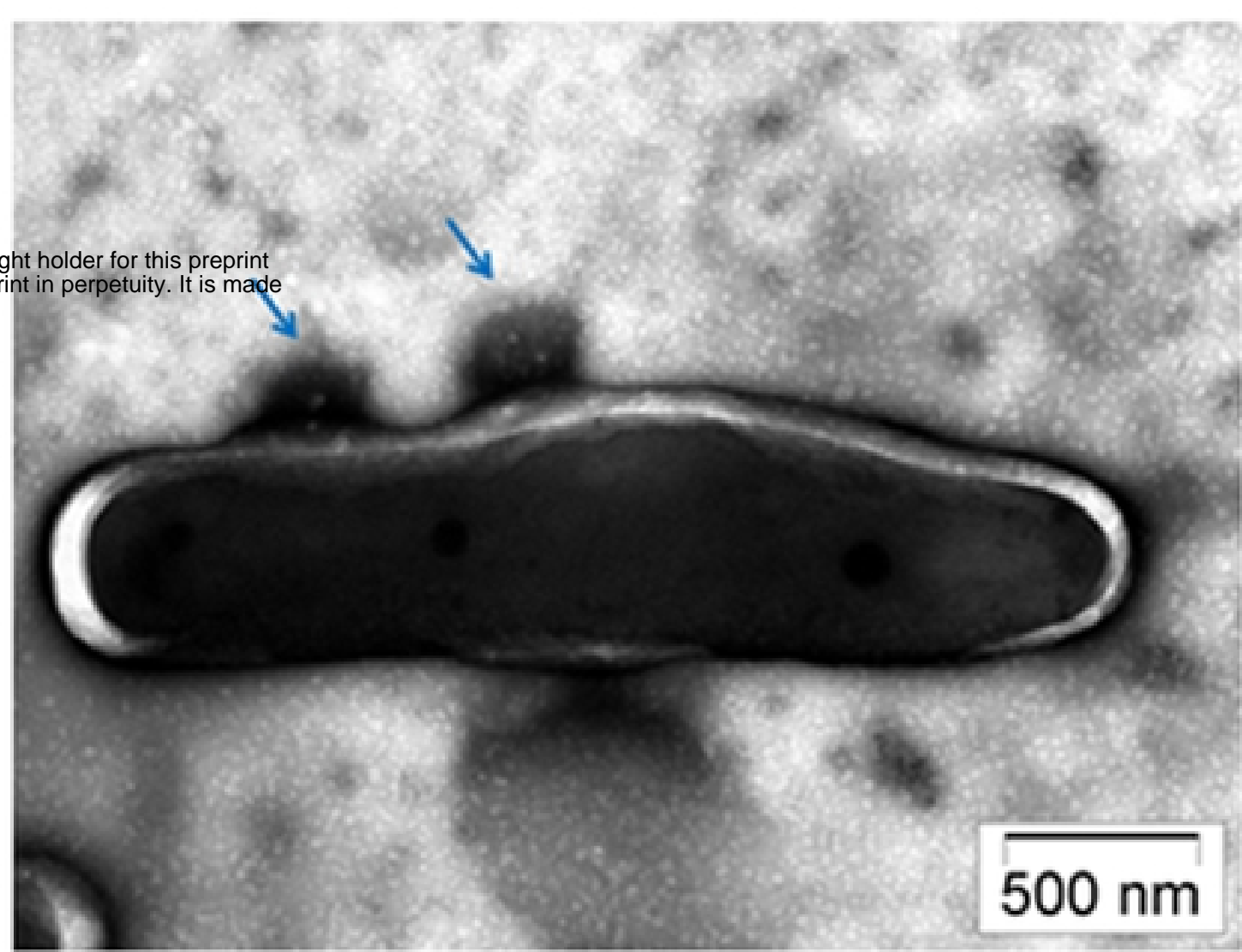

(B)

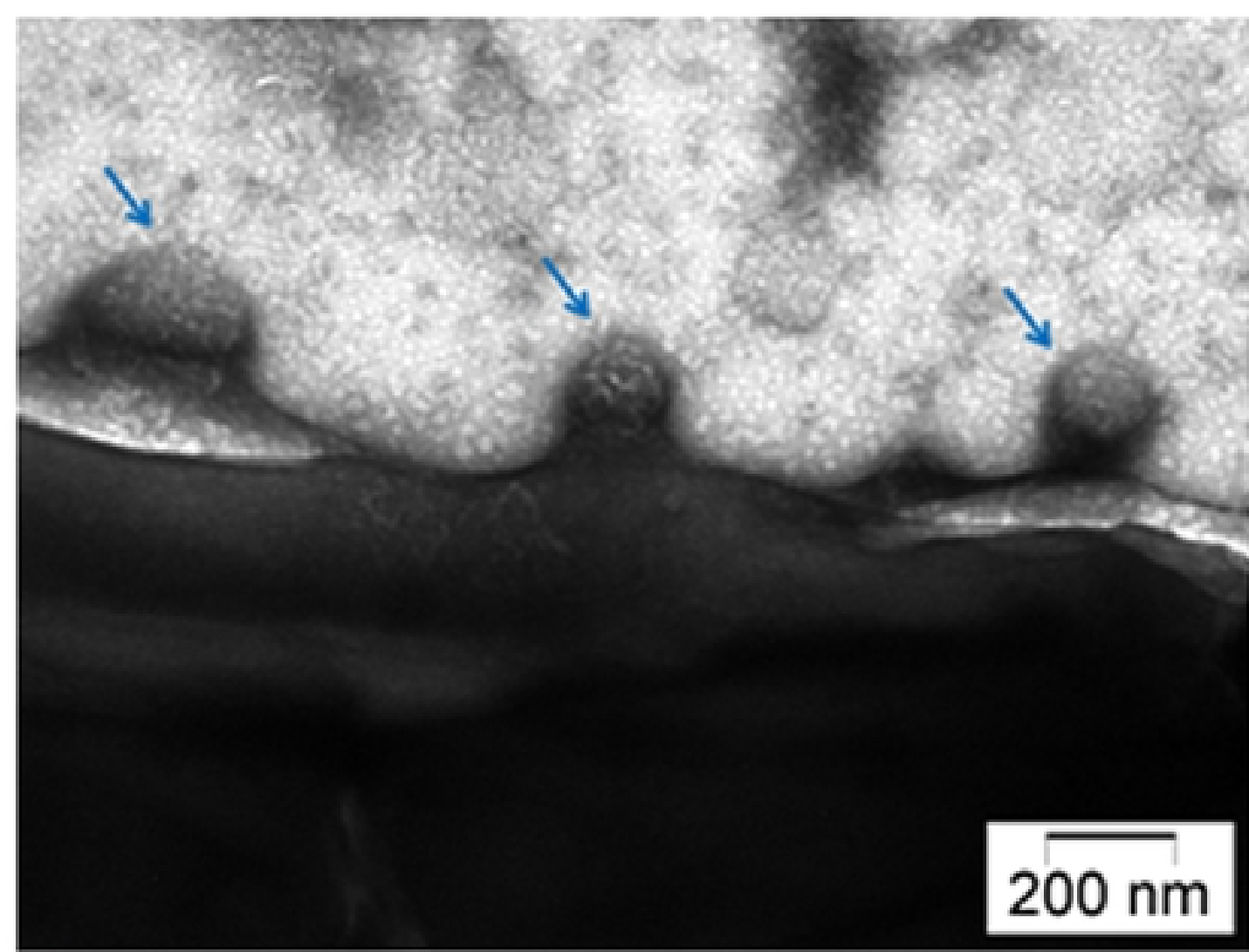

(C)

Figure 4 


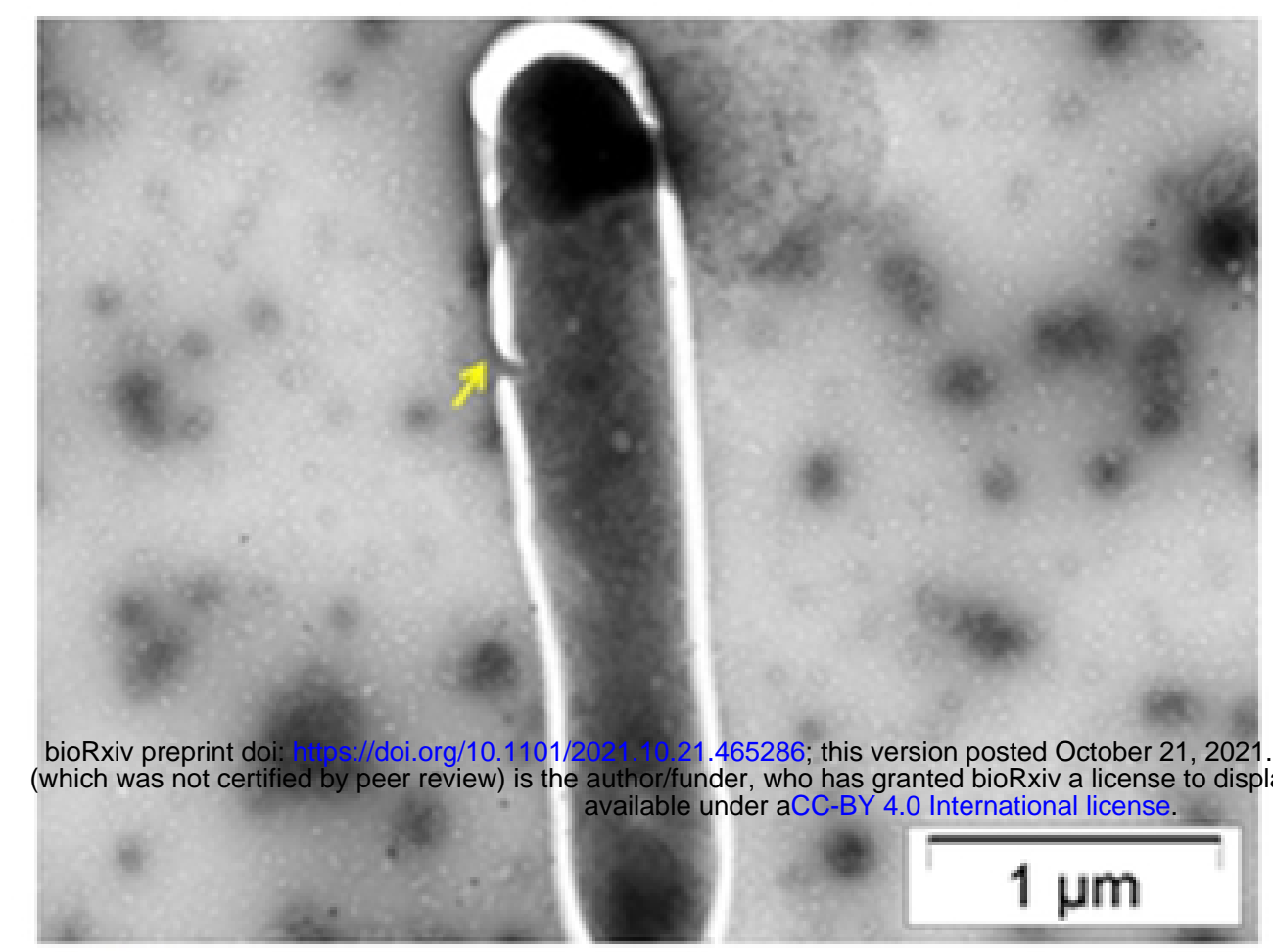

(A)

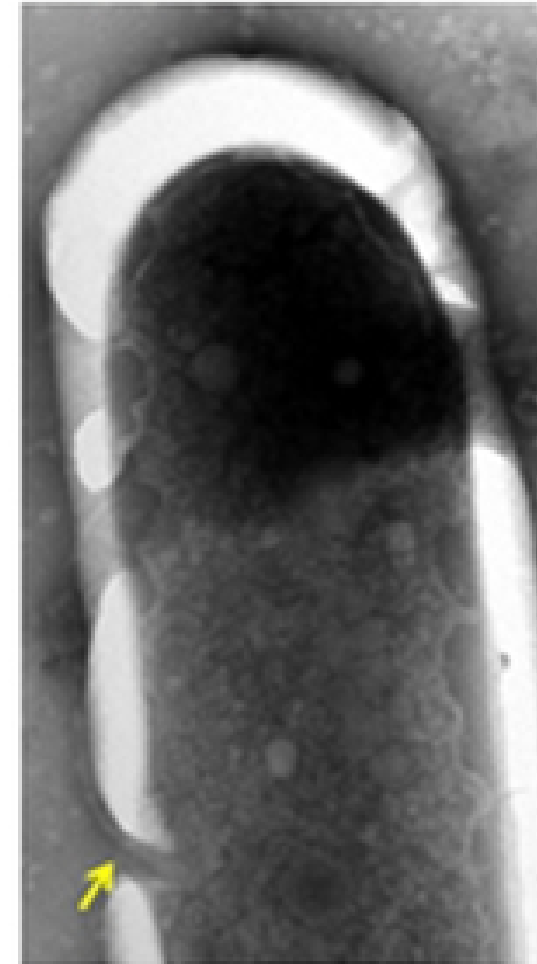

(C)

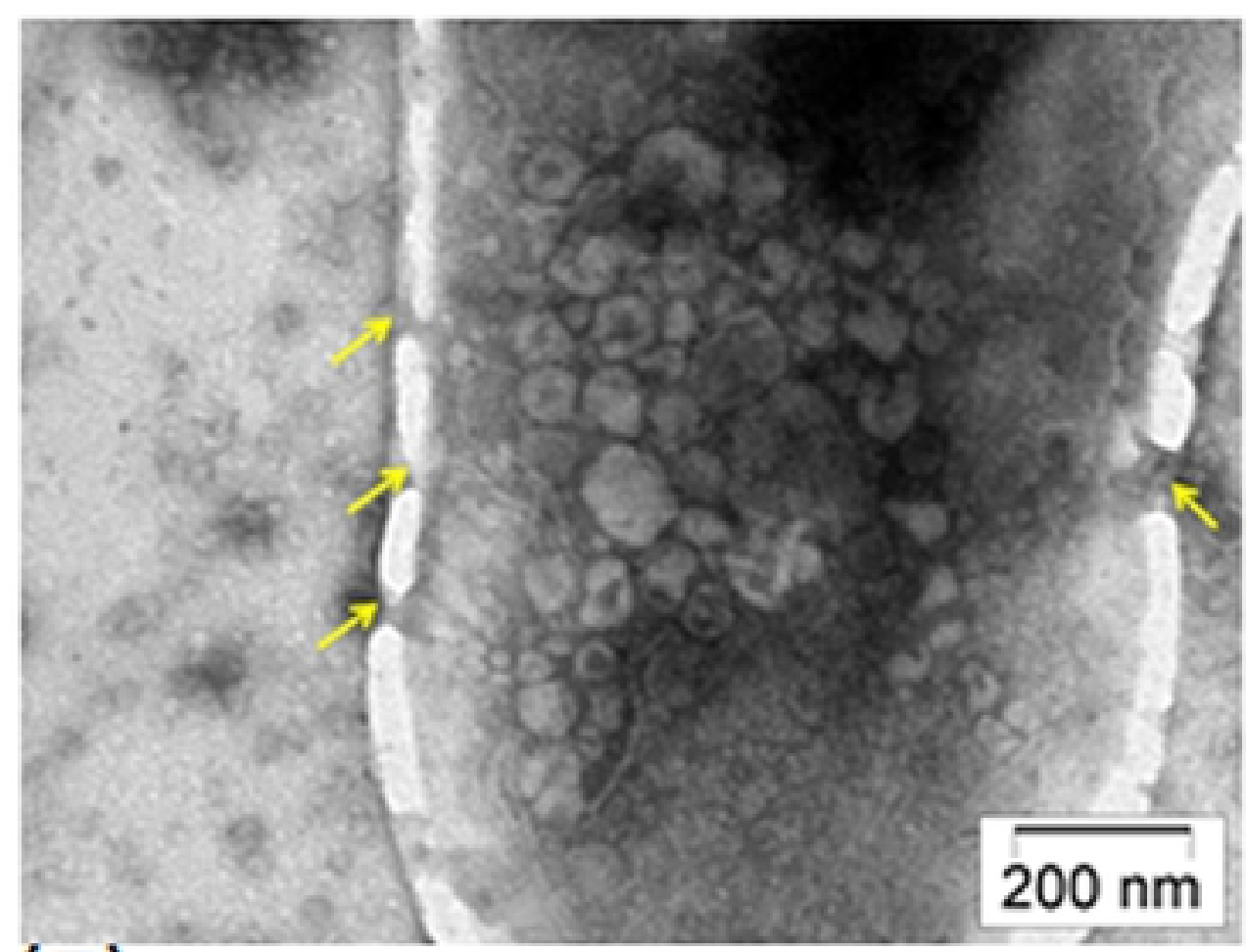

(E)

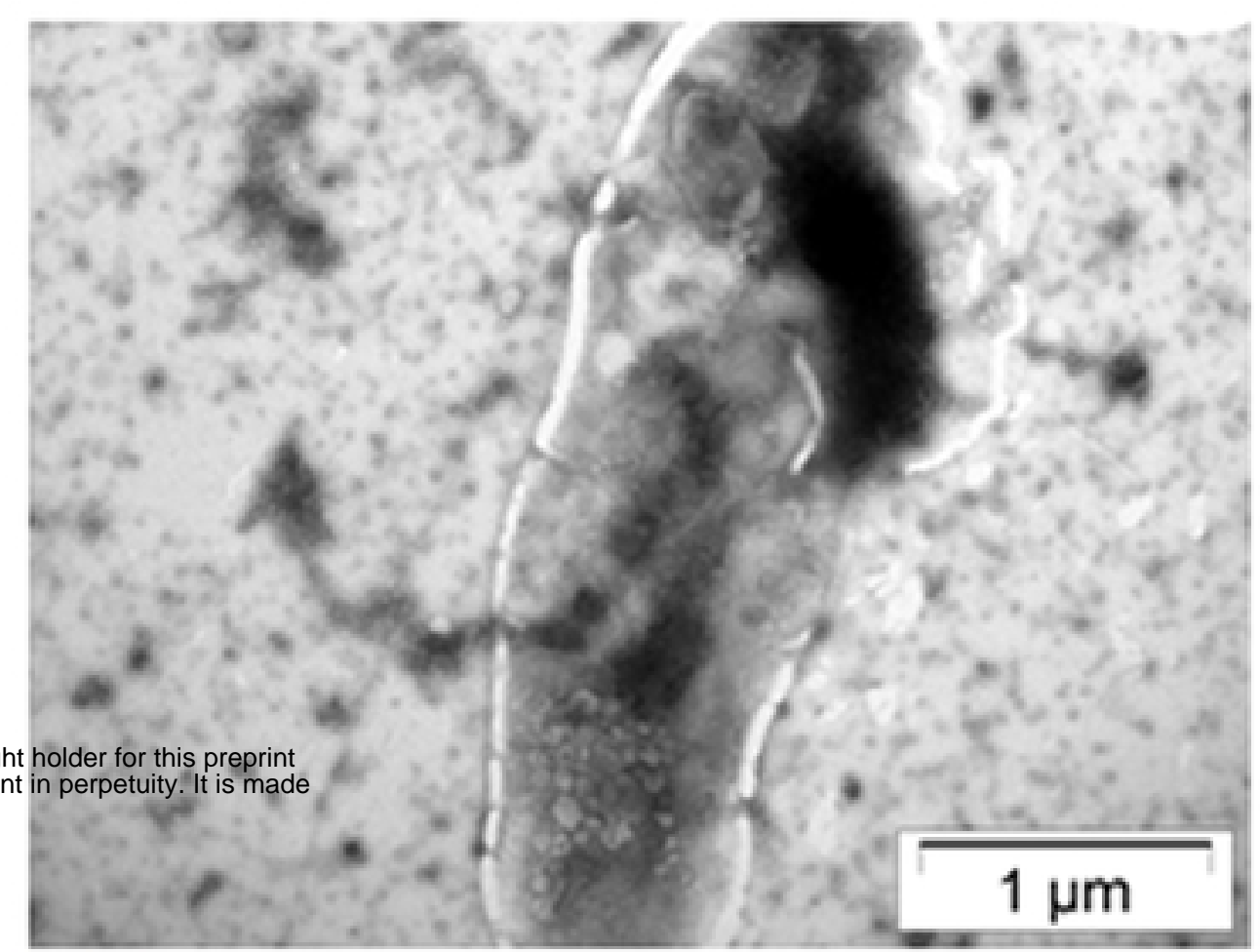

(B)

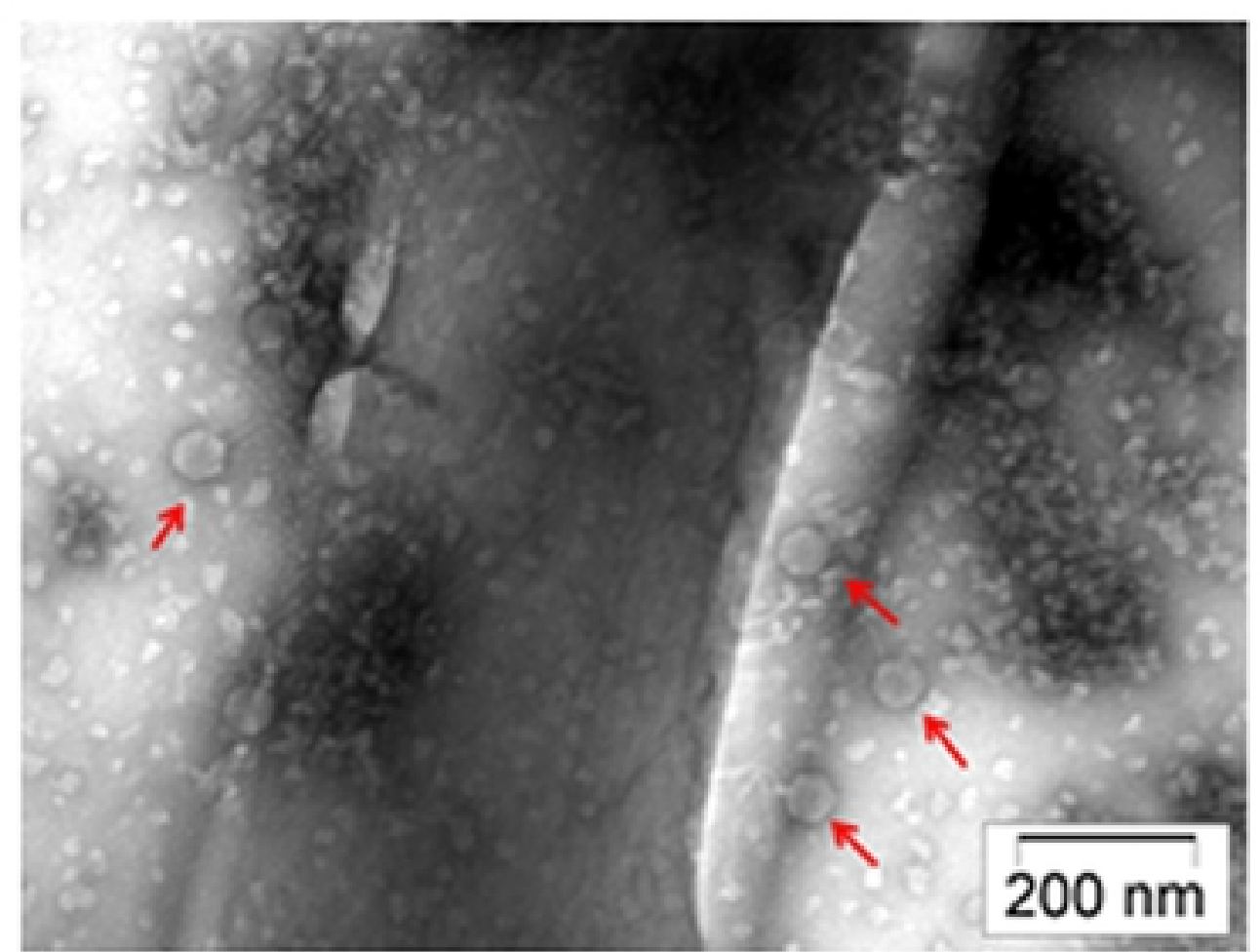

(D)

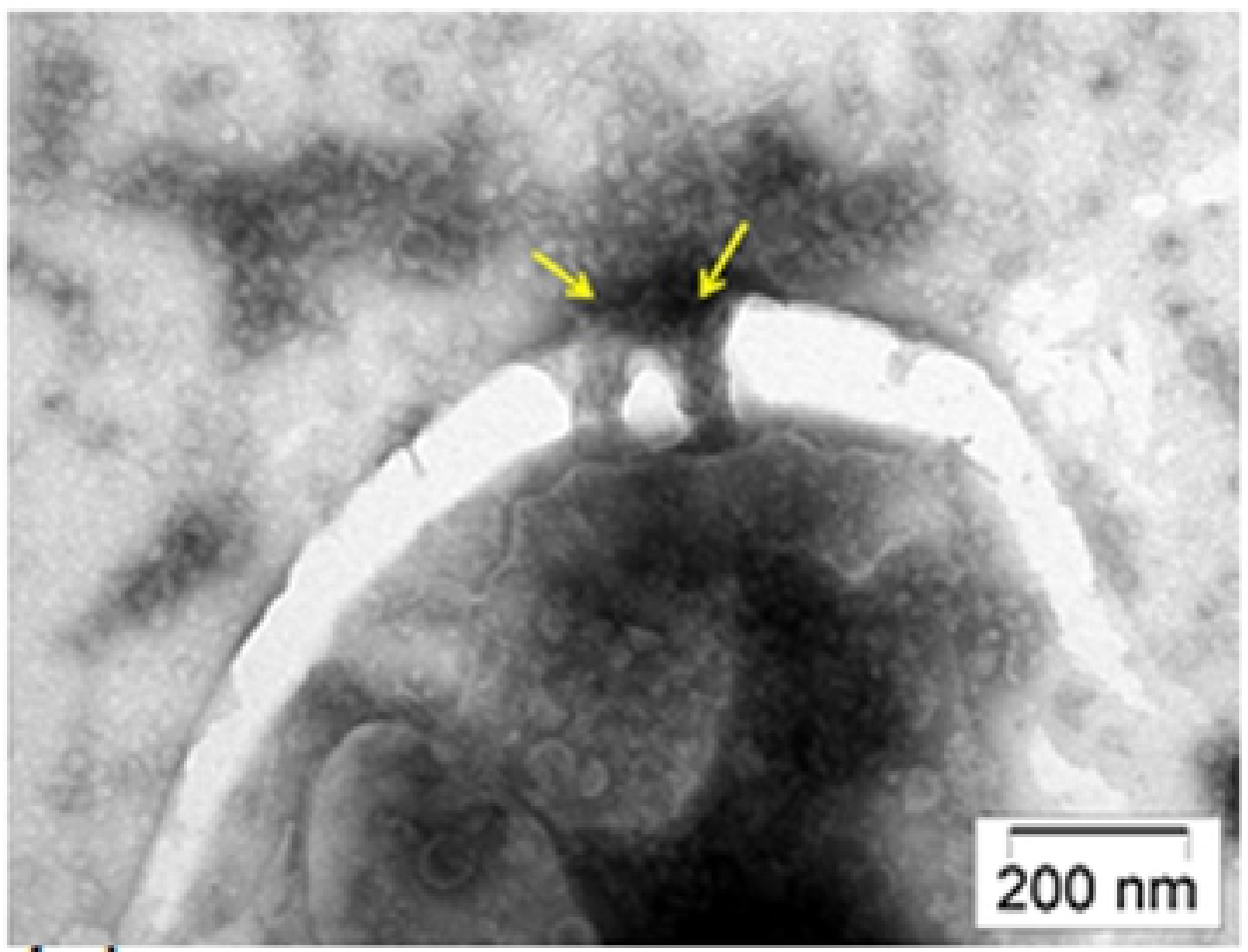

(F)

Figure 5 

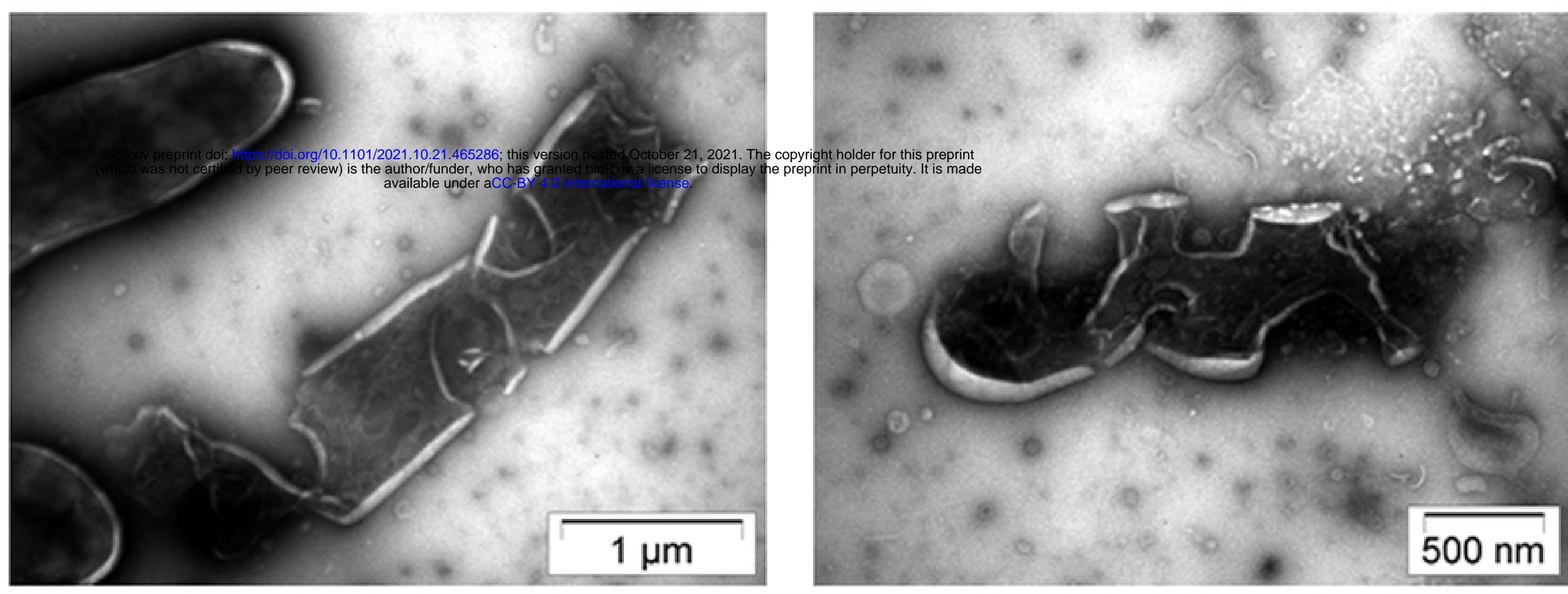

(A)

(B)

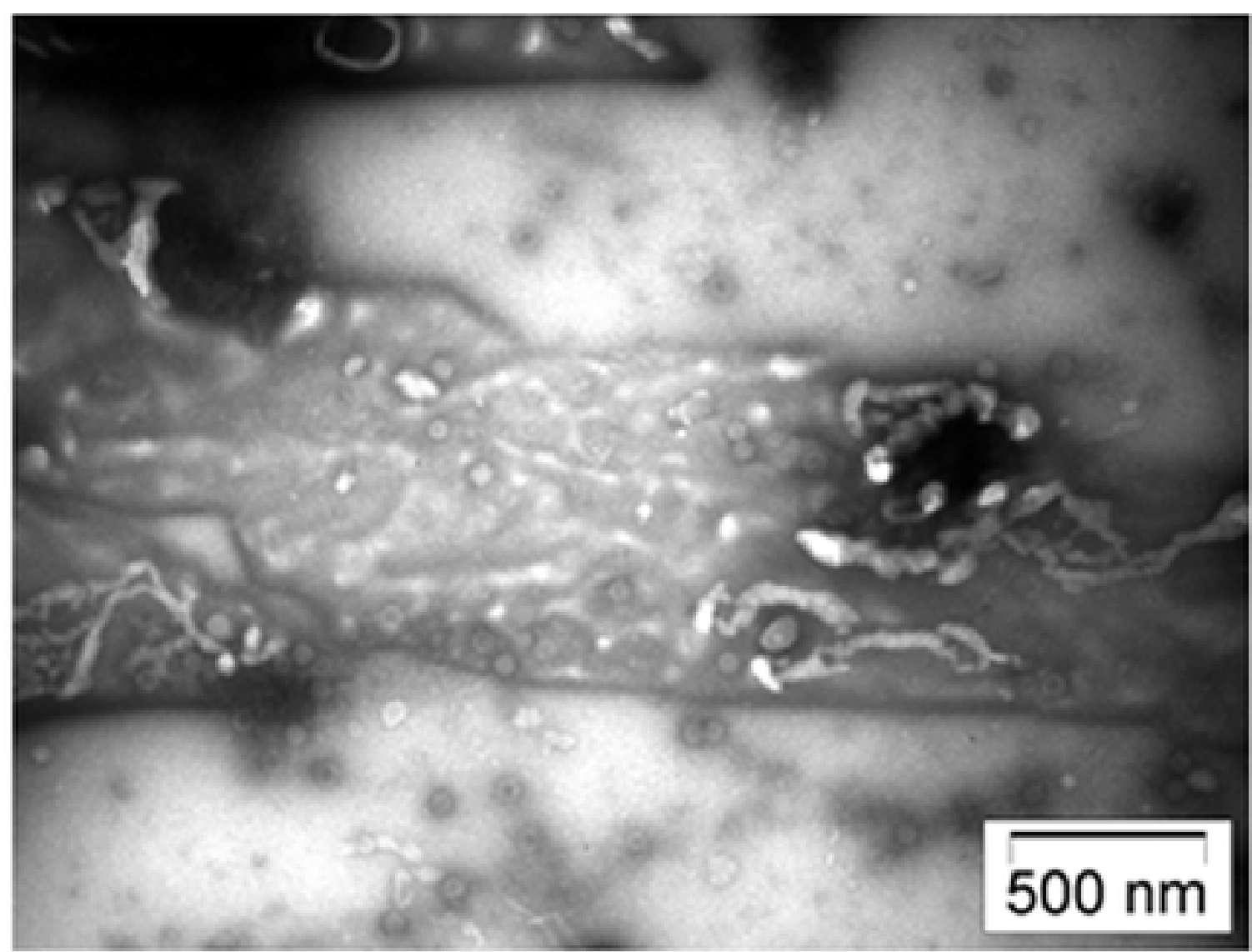

(C)

Figure 6 


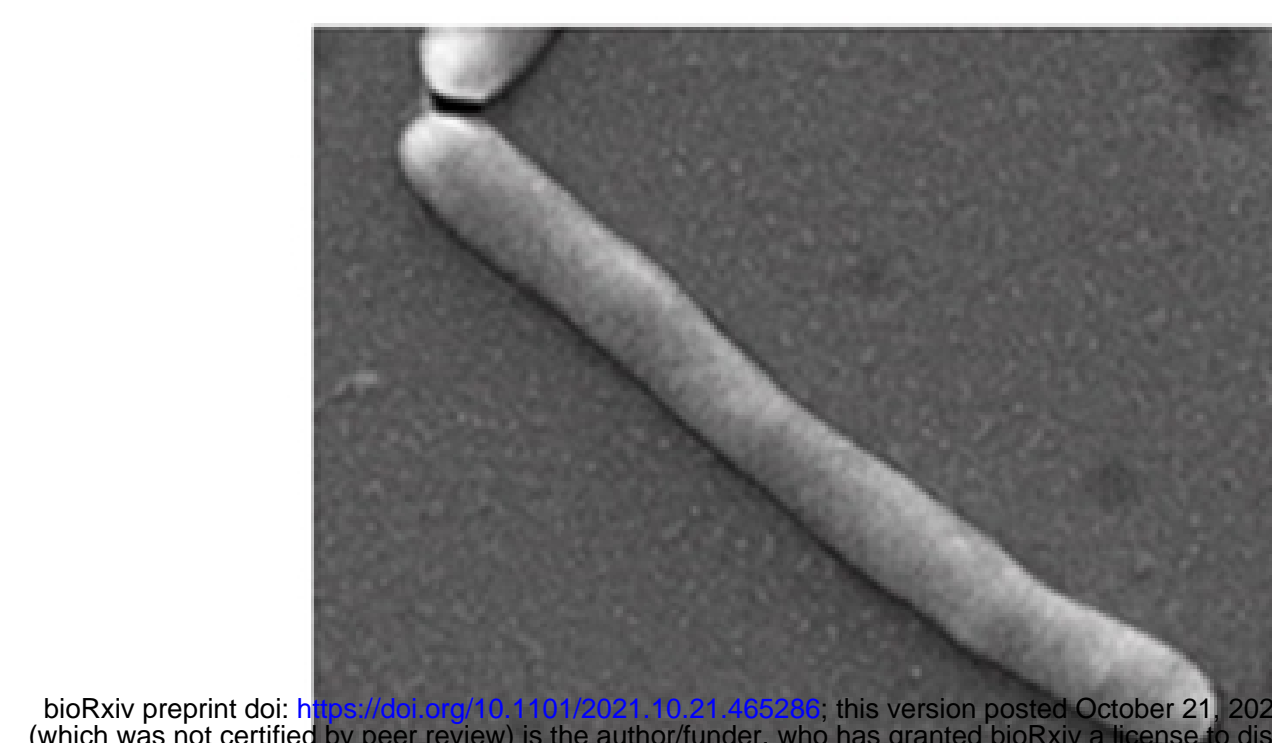

bioRxiv preprint do:

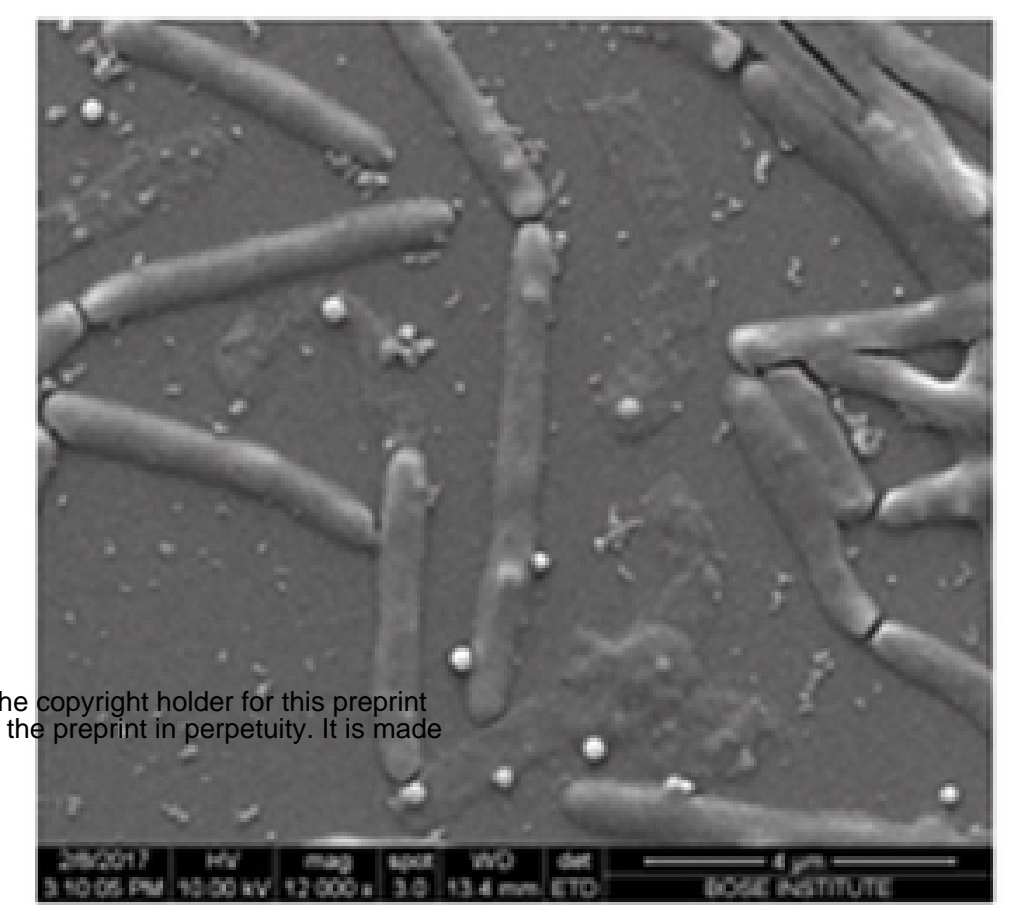

(A)

(B)
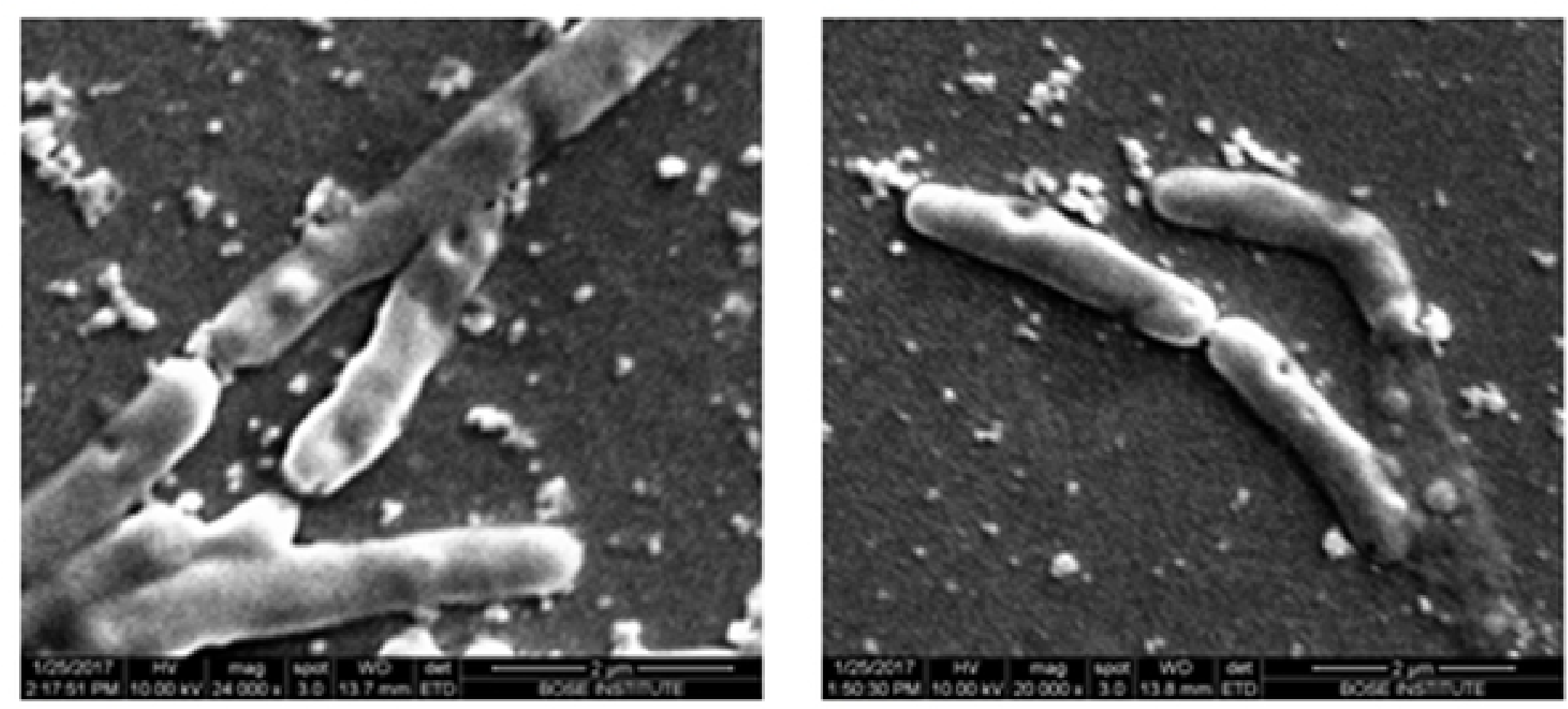

(C)

(D)

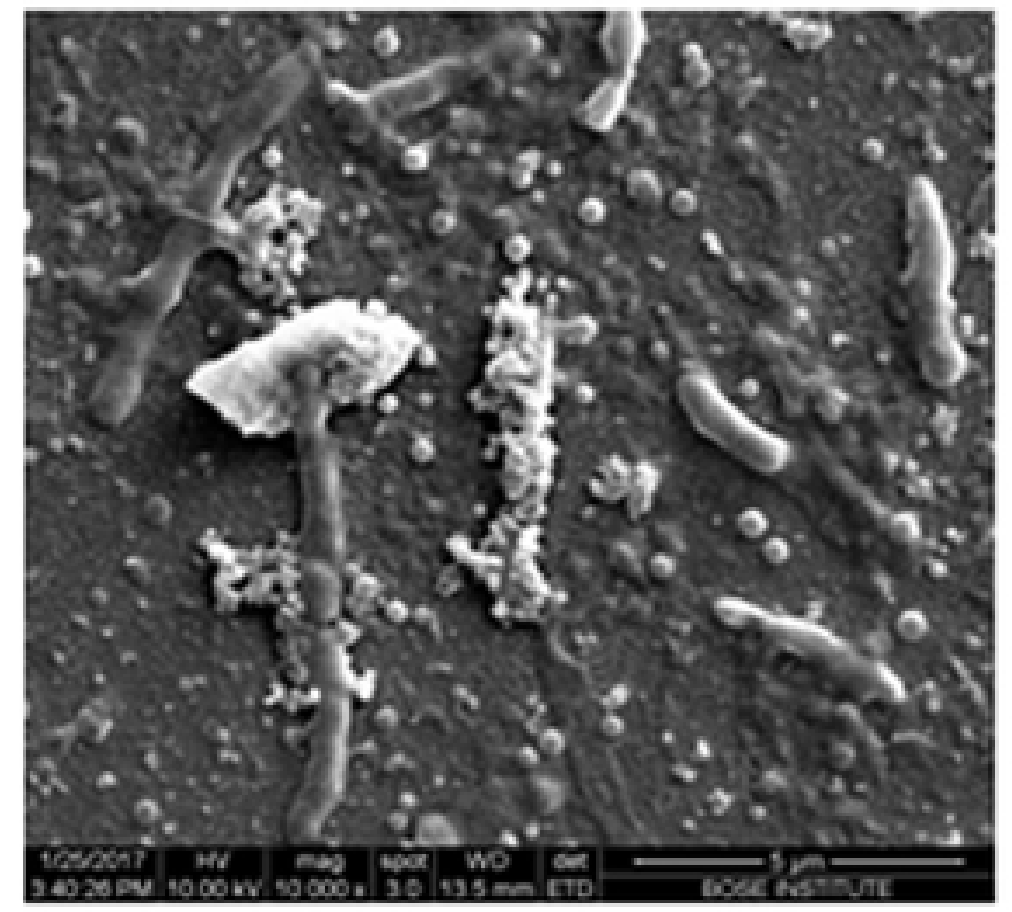

(E)

Figure 7 


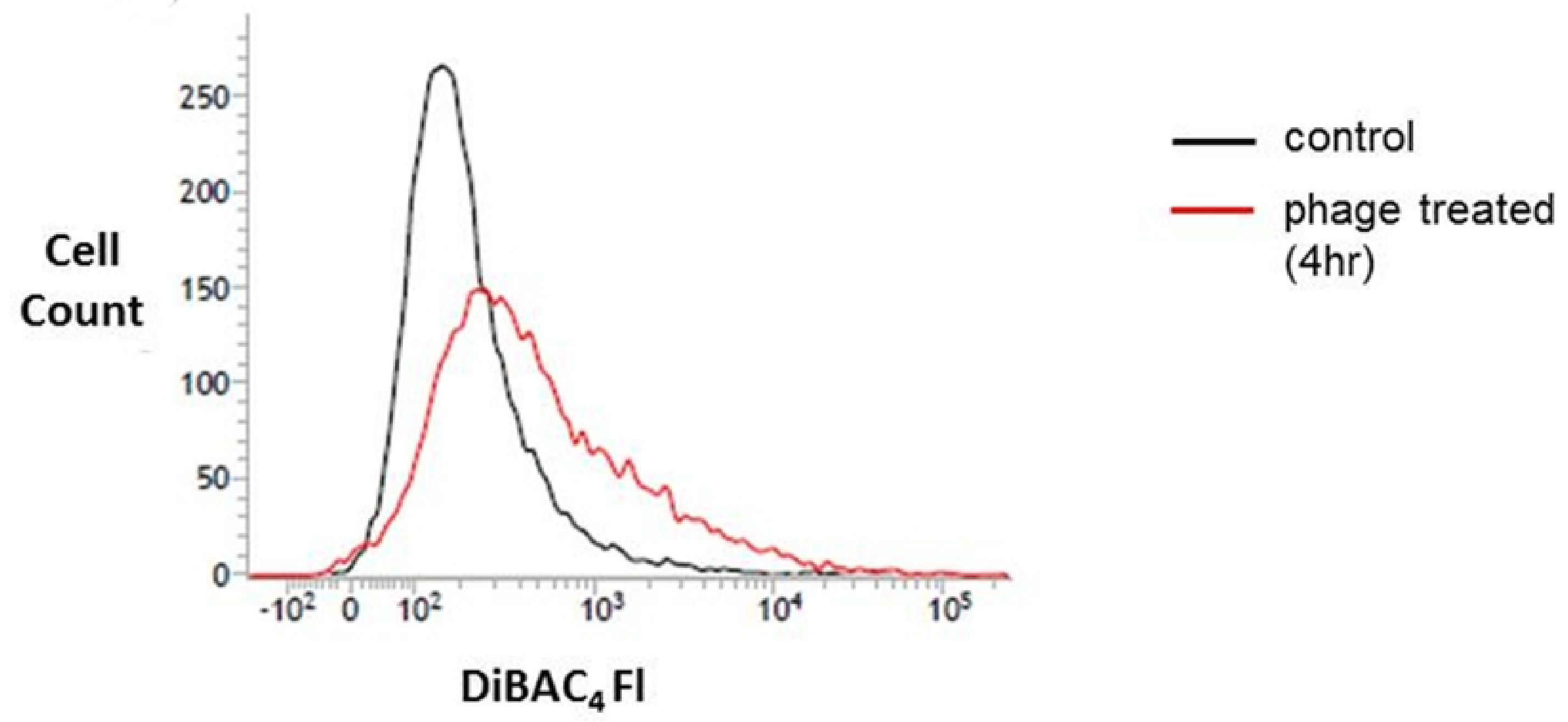

Figure 8 
Control

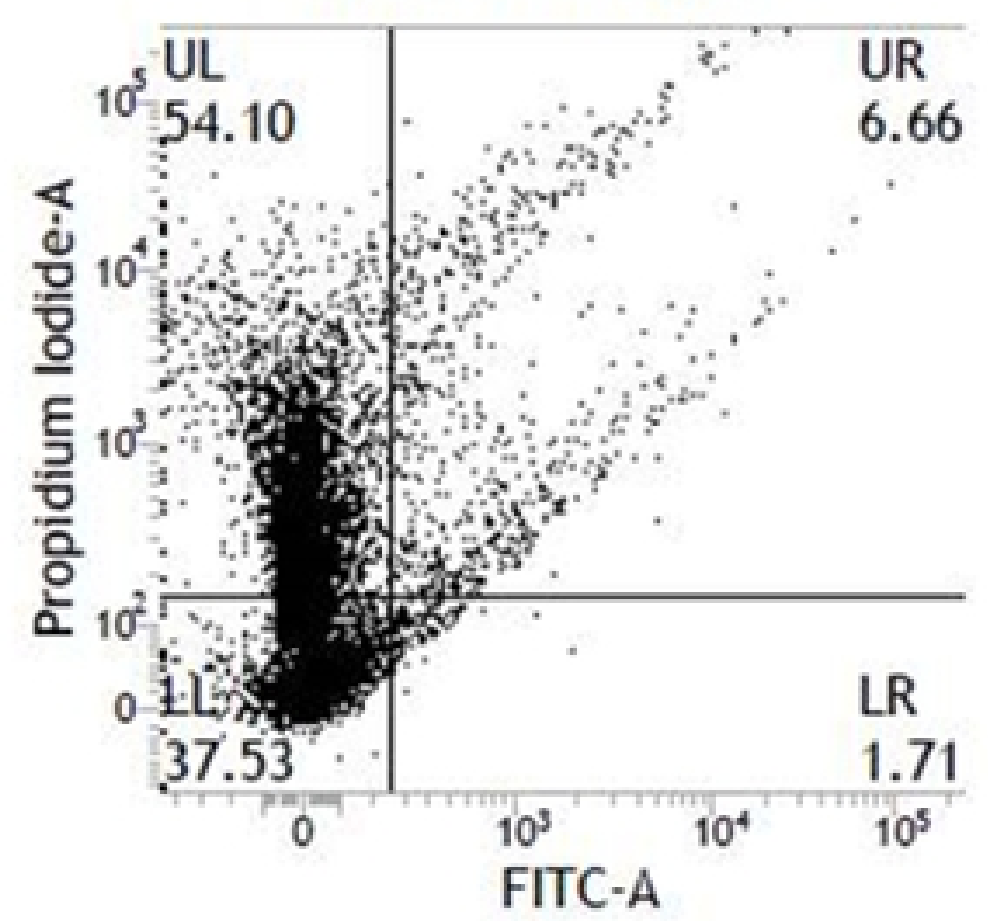

Phage treated (4hr)

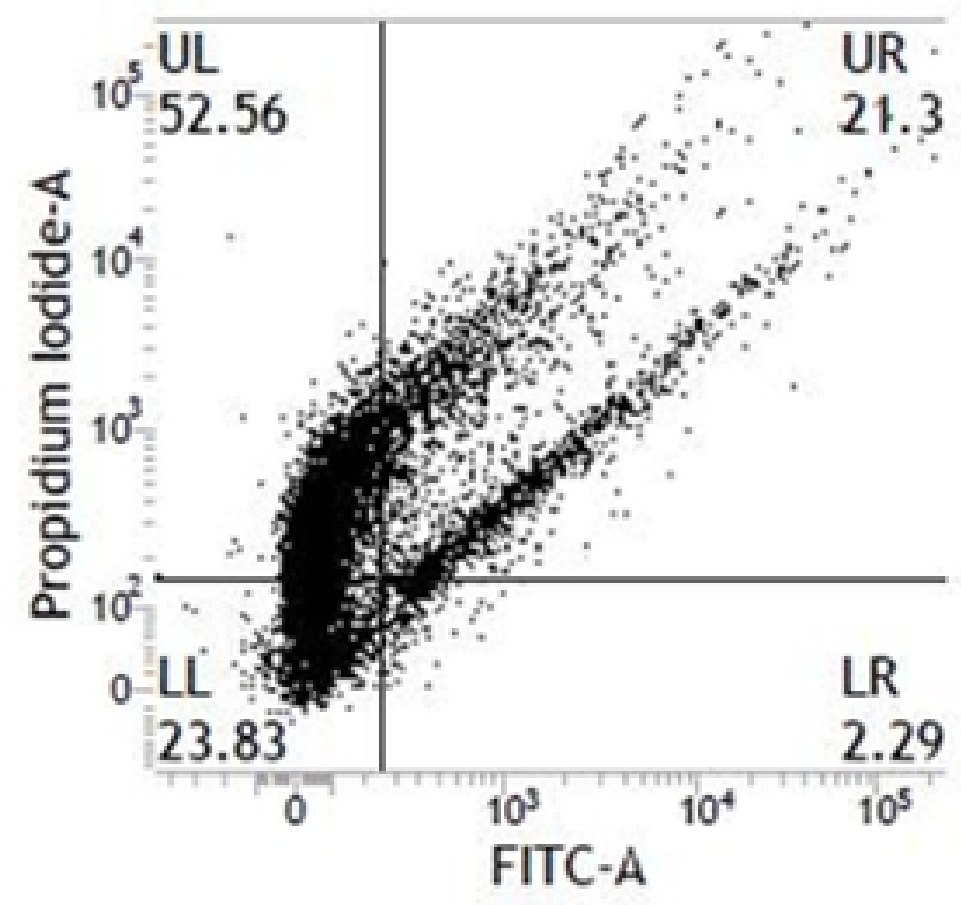

Figure 9 


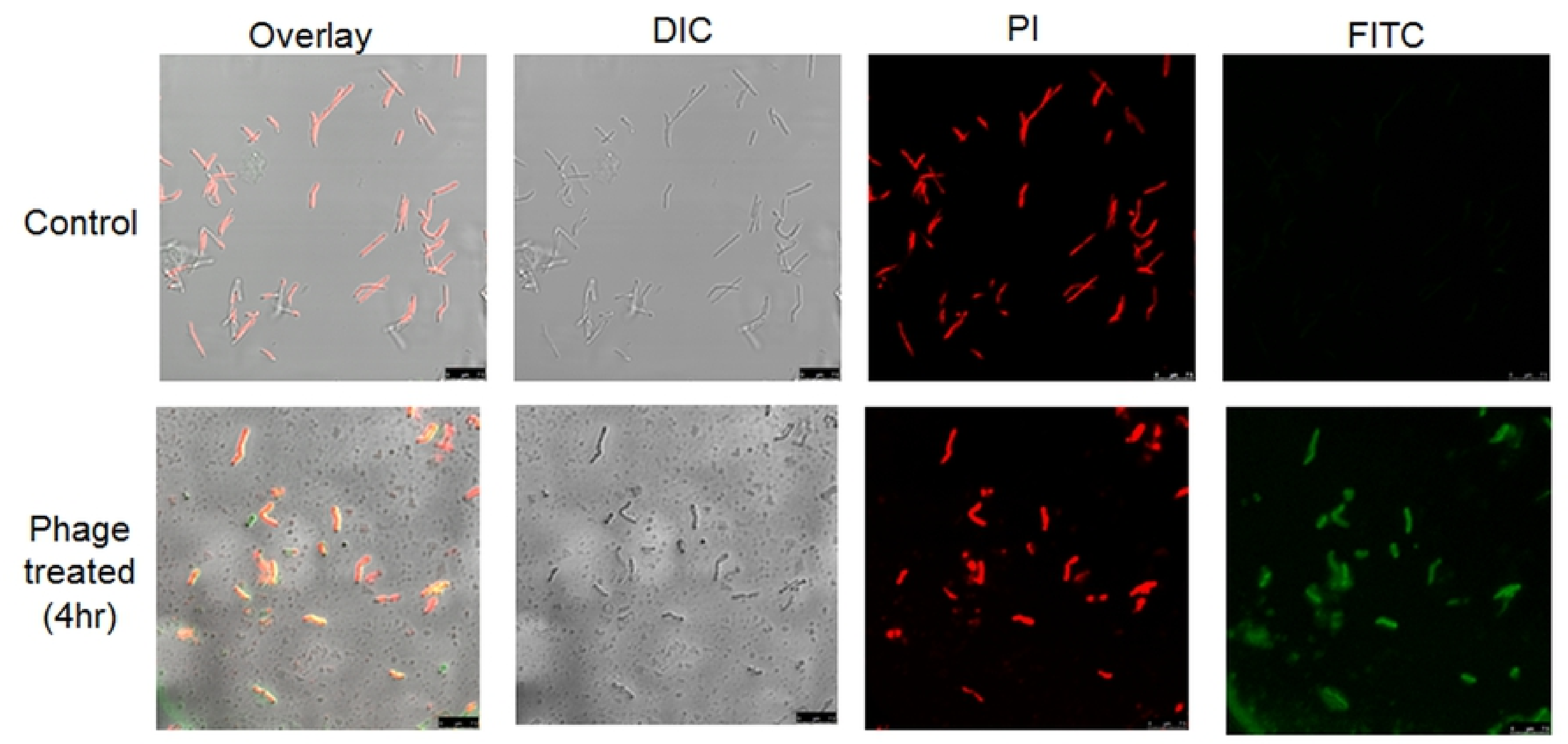

Figure 10 

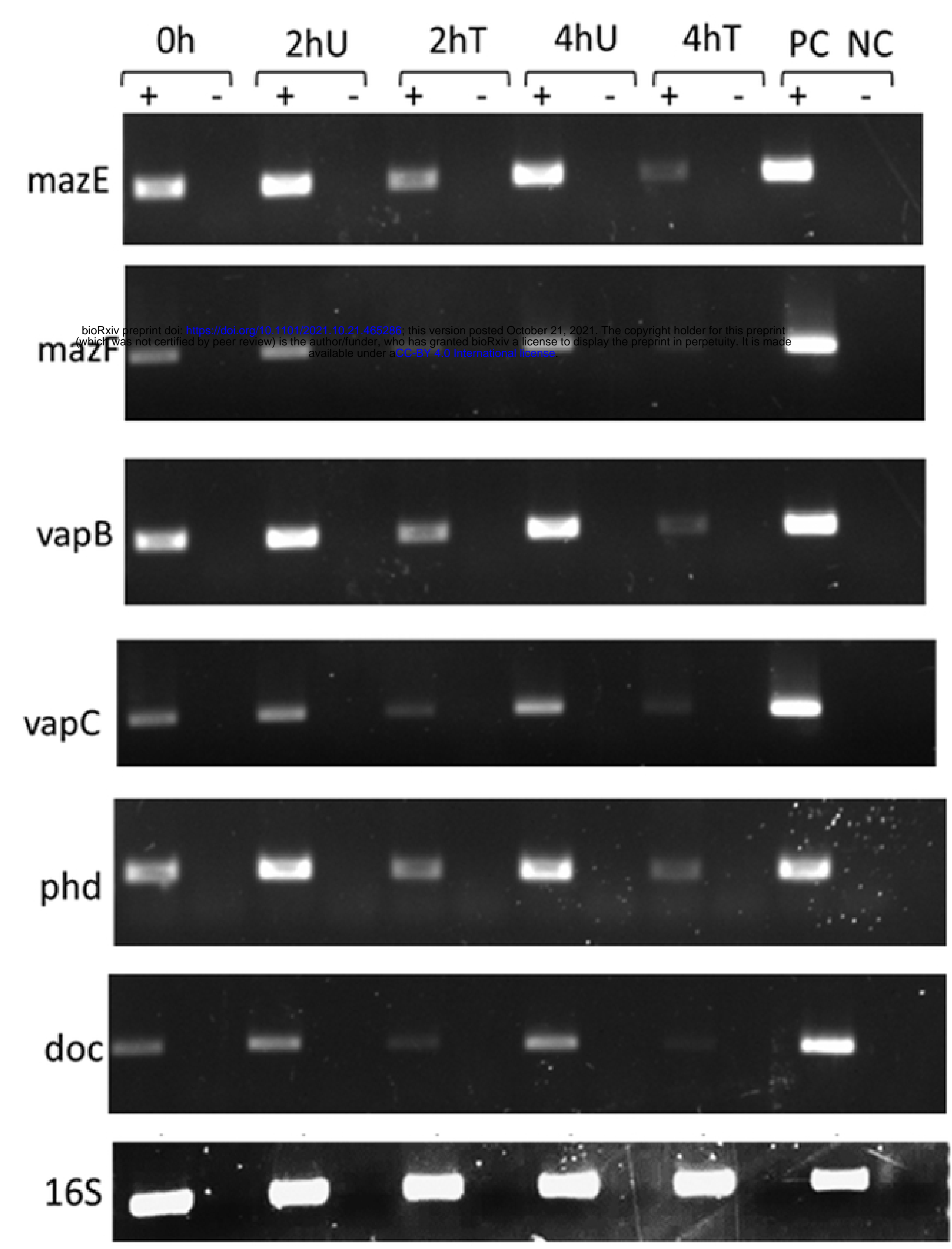

Figure 11 

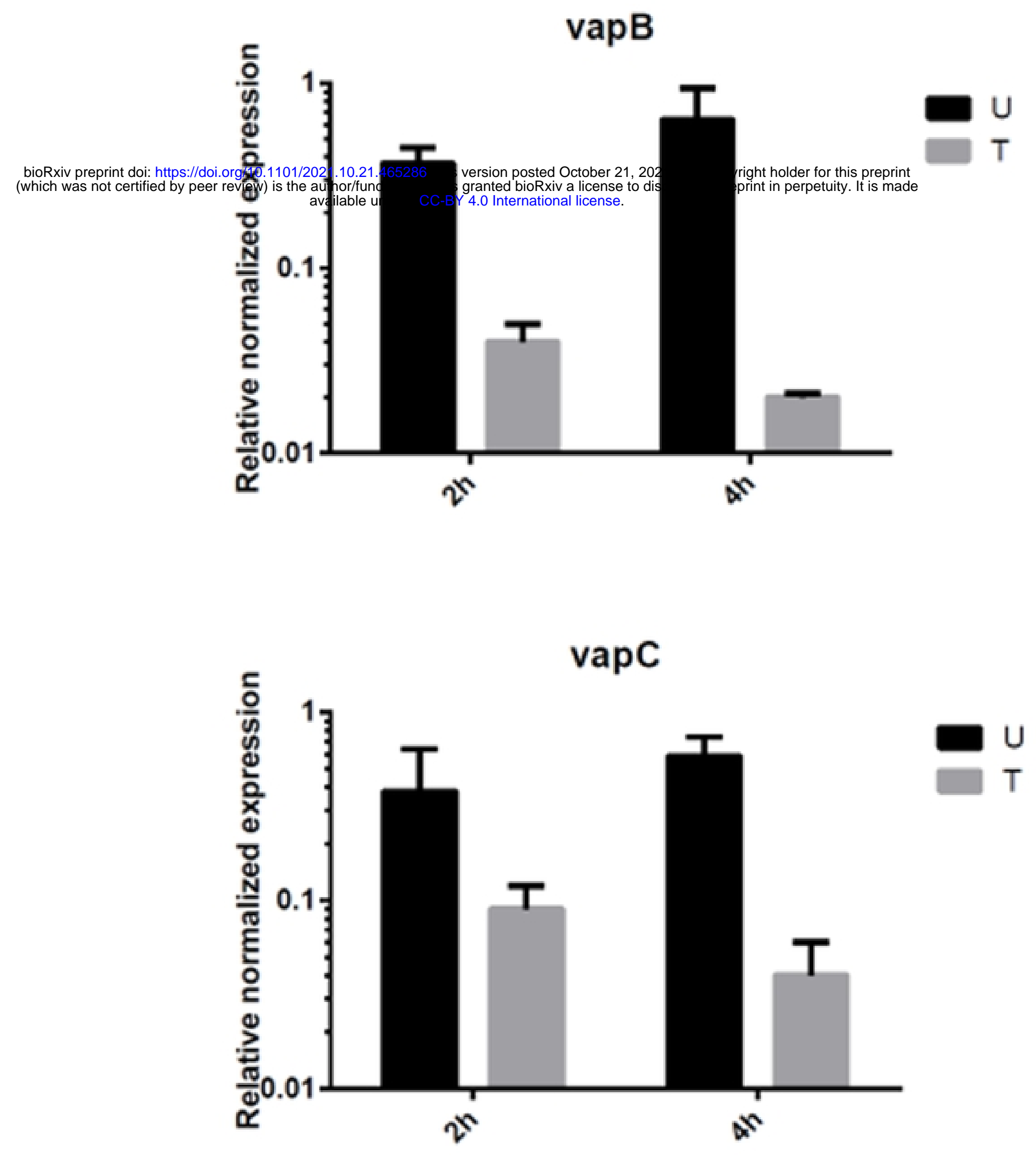

Figure 12 